ORIGINAL PAGE IS

OF POOR QUALITY

NASA/ASEE SUMMER FACULTY FELLOWSHIP PROGRAM

MARSHALL SPACE FLIGHT CENTER

THE UNIVERSITY OF ALABAMA

\title{
RADIATION EFJECT ON ROCKET ENGINE PERFORMANCE
}

\author{
Prepared by: \\ Academic Rank: \\ University and Department: \\ NASA/MSFC \\ Laboratory: \\ Division: \\ Branch : \\ MSFC Colleague: \\ Date: \\ Contract No.:
}

\author{
Huei-huang Chiu, Ph.D. \\ Professor \\ University of Illinois at Chicago \\ Department of Mechanical Engineering
Propulsion
Propulsion Systems
Performance Analysis \\ Klaus W. Gross \\ September 1988 \\ NGT-01-022-099 \\ The University of Alabama
}




\title{
RADIATION EFFECT ON ROCKET ENGINE PERFORMANCE
}

\author{
by \\ Hue i-huang Chiu \\ Professor of Mechanical Engineering \\ University of Illinois at Chicago \\ Chicago, Illinois
}

\begin{abstract}
The effects of radiation on the performance of modern rocket propulsion systems operating at high pressure and temperature have been recognized as a key issue in the design and operation of various liquid rocket engines of the current and future generations.

Critical problem areas of radiation coupled with combustion of bipropellants are assessed and accounted for in the formulation of a universal scaling law incorporated with a radiation-enhanced vaporization combustion model. Numerical algorithms are developed and the pertaining data of the Variable Thrust Engine (VTE) and Space Shuttle Main Engine (SSME) are used to conduct parametric sensitivity studies to predict the principal intercoupling effects of radiation. The analysis reveals that low enthalpy engines, such as the VTE, are vulnerable to a substantial performance set back by the radiative loss, whereas the performance of high enthalpy engines such as the SSME, are hardly affected over a broad range of engine operation. Additionally, combustion enhancement by the radiative heating of the propellant has a significant impact in those propellants with high absorptivity. Finally, the areas of research related with radiation phenomena in bipropellant engines are identified.
\end{abstract}




\section{ACKNOWLEDGMENTS}

I would like to extend my great appreciation to Mr. Klaus W. Gross, MSFC, who suggested these research topics and rendered valuable technical and scientific inputs on broad basic and practical issues in modern liquid rocketry. This collaborative effort has significantly broadened the scope and the depth of this preliminary research. Computational codes have been developed jointly by Mr. Gross and Mr. A. N. Krebsbach, and executed by Mr. Krebsbach. Their contributions form the base of the principal conclusion and are greatly appreciated. Special thanks are also due to Mr. Gross for his careful review of the manuscript and helpful suggestions. I wish to express my appreciation to the staffs of the Performance Analysis Branch, headed by $\mathrm{Mr}$. R. Bachtel, for their hospitality and generous support. The excellent opportunity and active research environment provided by NASA, MSFC, and ASEE during the summer program under the skiliful management of Ms. E. Cothran and Professor M. Freeman are graciously acknowledged. 


\section{INTRODUCTION}

The performance of modern rocket engines (Sutton and Ross, 1975) is primarily affected by the competitive rate processes involving multiphase turbulent reacting flow with phase change and heat transfer at an elevated chamber pressure, typically at $10^{3}$ psia and chamber temperatures of 5500 to $6500^{\circ} \mathrm{R}$ at which levels the flame emission (Afgan et al. 1974) due to the molecular gas radiation plays two significant roles. Firstly, the radiation emission leaving the system constitutes a thermal energy loss and, thus, directly and indirectly affects the major performance parameters through the chamber temperature. These performance parameters include critical mass flux, specific impulse $C^{*}$, and total thrust. Secondly, the radiative heating of propellants enhances the vaporization and combustion of droplets and, thus, the prosess serves to improve the overall combustion efficiency of the motors.

Because of these two diametrically opposite roles played by radia$t$ ion, the overall impact of flame emission may result in performance loss or gain depending on the relative preponderance of heat loss relative to propellant gasification rate enhancement. This constitutes the focal point of quantitative scrutinization.

The principal factors affecting the nature and extent of the irnpacts of radiation are traced down to the fundamental pinsics of ernission, absorption, and scattering of gas molecules, droplets, soot particles in hydrocarbon propellants, and the combined radiation and conduction-convection heat transfer in the chamber (Summarfield, 1960). The practical significance of the above-mentioned factors depends on the basic design and operating parameters including propellant properties, mass flow rates, mixture ratio, chamber pressure, spray characteristics, and the combustor size.

One of the critical design issues of the current and future rocket engines is the lack of a comprehensive criterion that predicts and classifies the motor performance characteristics, in the presence of the radiation processes, in terms of the design and operating parameters described above.

Review of the 1iterature accumulated over the past several decades reveals that there has been little or no in-depth research which pertains to the fundamental issues of radiation in liquid rocket combustion chambers. Furthermore, there has been a genuine lack of vital engineering data, modern analytical tools, and computational fluid dynamics (CFD) required for the analysis of the bipropellant and monopropellant combustion processes. In fact, many of the existing data and analytical tools developed for the radiative treatment of large scale industrial combustion appliances (Afgan et al., 1974) and air breathing engines are incomplete and inadequate for application in rocket motors for performance and design optimization. To this end, a comprehensive 
motor performance scaling law is developed, on the basis of rudimental thermodynamic and combustion principles, to aid in assessment and identification of the basic issues and qualitative prediction of the motor performance characteristics of modern liquid rocket engines.

The objectives of this study are (1) to develop an algebraic scaling law of motor performance and propellant droplet gasification laws, (2) to assess and compare the performance of the VTE and SSME with respect to regenerative heat recovery systems in each type of engine, and (3) to identify specific technical problem areas where radiation modeling and numerical simulation of radiation-coupled combustion processes are required. 


\section{SCALING LAWS OF ROCKET MOTORS}

A performance scaling 1 aw is developed with (1) thermodynamic relationships that determine the chamber temperature as a function of propellant properties, chamber inlet conditions, wall heat transfer by conduction, convection, and radiation, combustion and vaporization efficiencies, and a regenerative efficiency; and (2) propellant droplet laws that predict the rate of vaporization and combustion under the effects of combined radiation and conductive heat transfer.

Such a law must preserve the universality for any type of propellants and engine configuration, regenerative or non-regenerative, and a11 engine power levels.

\subsection{Thermodynamic Performance Mode1}

A schematic, Figure 1 ( $a$ and $b$ ), shows a regenerative rocket engine that admits fuel and oxidizer at flow rate $\dot{\mathrm{m}}_{\mathrm{F}}$ and $\dot{\mathrm{m}}_{0}$, respectively, at an effective inlet temperature $T_{i}$. The reheater receives heat at the rate of $q_{R}$, radiative heat, and $q_{C}$, conductive heat, from the bulk of the gas in the combustion chamber. The fraction of heat received, $\eta_{n}$ $\left(q_{R}+q_{C}\right)$, is used in propellant preheating and the remaining part is lost to the environment. The bipropellants enter the motor at a temperature $T_{i}^{\prime}$ and gasify at the efficiency of $\eta_{F V R}$ for fuel, and $\eta_{\text {OUR }}$ for oxidizer, respectively. The overall combustion efficiency is $\eta_{\mathrm{CR}}$. The subscript $R$ reflects the inclusion of the radiation effects during the phase change and propellant combustion. The heat released by combustion raises the temperature of the gas product, $T_{C}$, and partly transfers heat to the wall by conduction $\mathrm{q}_{\mathrm{C}}$ and radiation $\mathrm{q}_{\mathrm{R}}$. Thus, $\mathrm{T}_{\mathrm{C}}$ is, in general, lower than the adiabatic flame temperature. The flame emission from the hot combustion zone is assumed to be uniformly distributed in the chamber and is transported to the wall, held at the temperature $T_{W}$.

\subsubsection{Scaling Law of Rocket Motor Performance}

The overall energy balance of a rocket motor is given by

$$
\begin{gathered}
\dot{\mathrm{m}}_{\mathrm{f}}(1+\phi) \mathrm{C}_{\mathrm{P}}\left(\mathrm{T}_{\mathrm{C}}-\mathrm{T}_{\mathrm{i}}{ }^{\prime}\right)=-\mathrm{q}_{\mathrm{C}}-\mathrm{q}_{\mathrm{R}}+\mathrm{n}_{\mathrm{C}} \dot{\mathrm{m}}_{\mathrm{f}}(1+\phi) \mathrm{Q}_{\mathrm{C}} \\
-\dot{\mathrm{m}}_{\mathrm{f}}\left(\eta_{\mathrm{VFR}} \mathrm{L}_{\mathrm{F}}+\phi \eta_{\mathrm{VOR}} \mathrm{L}_{0}\right)
\end{gathered}
$$




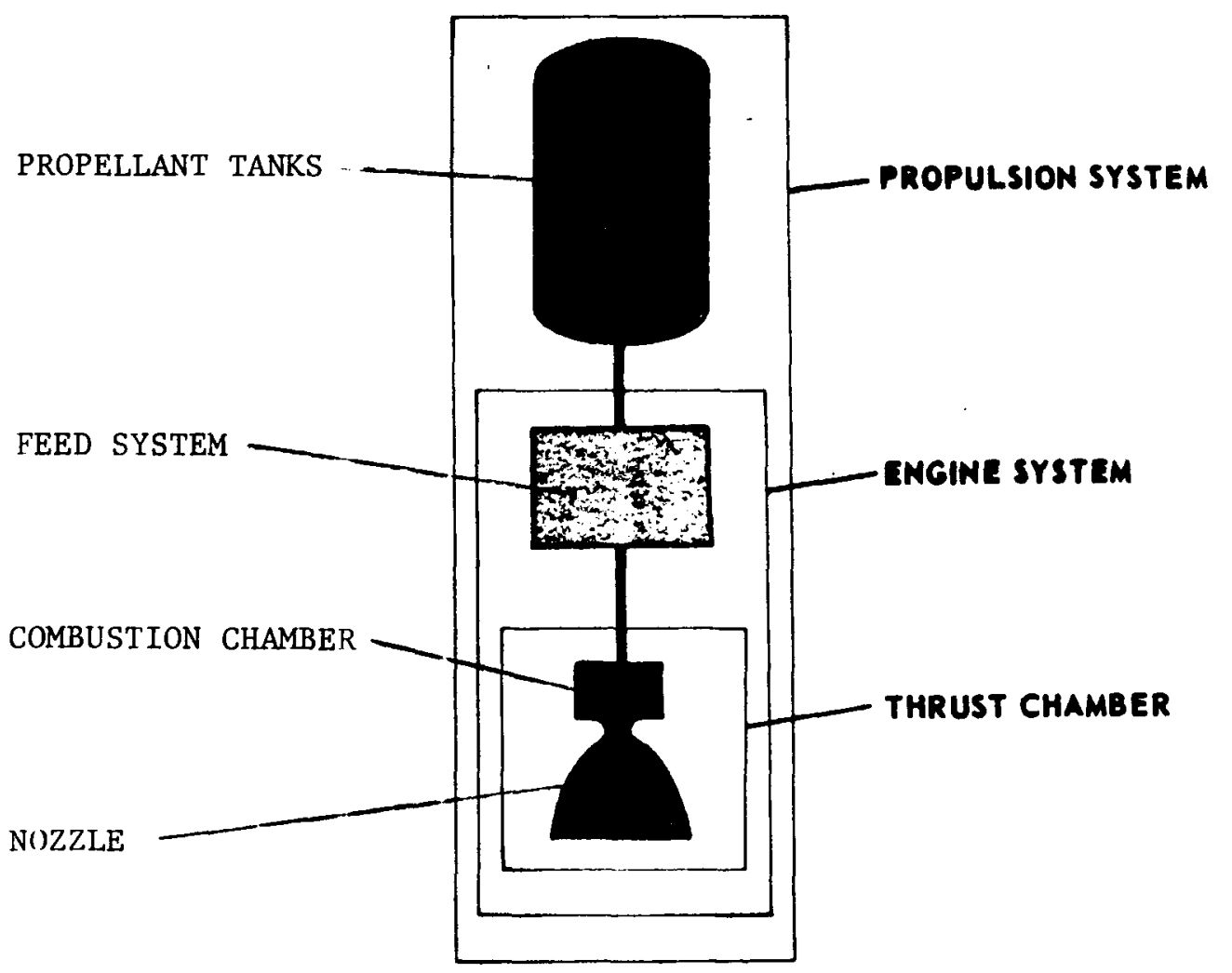

Fig. 1(a). Schematic of Liquid Propulsion System

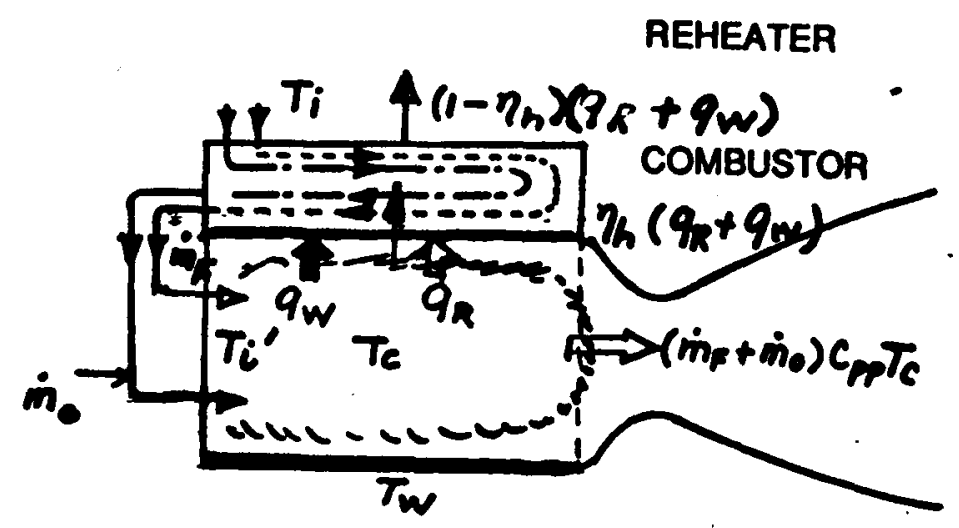

Fig. 1(b). Schematic of Thrust Chamber

ORIGINAL PAGE IS OF POOR QUALITY 


\section{ORIGINAL PAGE IS \\ OF POOR QUALITY}

and for the reheater

$$
\eta_{h}\left(q_{C}+q_{R}\right)=\dot{m}_{f}(1+\phi) c_{P}\left(T_{i}^{\prime}-T_{i}\right)
$$

where the wall heat transfer rates $q_{C}$ and $q_{R}$ are

$$
\begin{aligned}
& q_{C}=\frac{\pi N_{u} k L}{2}\left(T_{C}-T_{W}\right) \\
& q_{R}=\sigma \pi D L\left(\varepsilon_{g} T_{C}^{4}-a_{W} T_{W}^{4}\right)
\end{aligned}
$$

$\phi$ is the mixture ratio, $\mathrm{N}_{\mathrm{u}}$ is the Nusselt number, $\mathrm{k}$ is the thermal conductivity of the gas, $\varepsilon$ is the emissivity, $\sigma$ is the Steinan-Boltzmann constant, $a$ is the surface absorptivity, $D$ is the diameter, and $L$ is the length of the chamber, respectively.

By eliminating $\mathrm{T}_{i}$ ' between equations (1) and (2) and by adopting a non-dimensionalization of the resulting equation with appropriate reference properties, one obtains the following algebraic scaling law:

$$
\gamma \theta_{C}^{4}+\theta_{C}=k
$$

where

$$
\begin{aligned}
& \gamma=\frac{\beta\left(1-\eta_{h}\right)}{1+\alpha\left(1-\eta_{h}\right)} \\
& K=\frac{1+\theta_{i}+\alpha\left(1-\eta_{h}\right) \theta_{W}+\beta_{W}\left(1-\eta_{h}\right) \theta_{W}^{4}}{1+\alpha\left(1-\eta_{h}\right)} \\
& \alpha=\frac{N_{u} k \pi L}{2 C_{P} \dot{m}_{f}(1+\phi)}=\frac{N_{u} k \pi L C^{*}}{2 C_{P} P_{C} A_{t}}
\end{aligned}
$$




$$
\begin{aligned}
& \beta=\frac{\sigma \varepsilon \pi \mathrm{DLQ} \mathrm{Q}_{\mathrm{E}}^{3}}{\mathrm{C}_{\mathrm{P}}{ }^{4} \dot{\mathrm{m}}_{\mathrm{f}}(1+\phi)^{4}}=\frac{\sigma \varepsilon \pi \mathrm{DLQ} \mathrm{Q}_{\mathrm{E}}{ }^{3} \mathrm{C}}{\mathrm{C}_{\mathrm{P}}{ }^{4} \mathrm{P}_{\mathrm{C}} \mathrm{A}_{\mathrm{t}}(1+\phi)^{3}} \\
& \beta_{W}=\frac{\sigma a_{W} \pi D L Q_{E}^{3}}{C_{P}^{4} \dot{m}_{f}(1+\phi)^{4}}=\frac{\sigma a_{W} \pi D L Q_{E}{ }^{3} C^{*}}{C_{P}^{4} P_{C} A_{t}(1+\phi)^{3}} \\
& \theta=\frac{(1+\phi) C_{P} T}{Q_{E}} \\
& Q_{E}=(1+\phi) \eta_{C} Q_{C}-\left(\eta_{V F R} L_{F}+\phi \eta_{V O R} L_{O}\right)
\end{aligned}
$$

in which $C_{P}$ is the specific heat of the combustion product, $C *$ is the characteristic exhaust velocity, $A_{t}$ is the throat area, $L_{F}$ and $L_{0}$ are the latent heat of vaporization of the fuel and oxidizer, respectively, $\phi$ is the mixture ratio, $\mathrm{P}_{\mathrm{C}}$ is the chamber pressure, and $\mathrm{k}$ is the thermal conductivity of the gas.

\subsubsection{Conductive and Convective Heat Transfer}

The conductive and convective heat transfer in rocket motors has been correlaled by various semi-empirical expressions involving the Nusselt number. For example, the Colburn equation gives an expression of the Nussejt number in terms of the Reynolds number and Prandt 1 number. In some sophisticated empirical laws, the effects of the boundary layer temperature gradient on the various gas properties near the chamber wall are accounted for. For example, Bartz (1958) gives the following semi-empirical formula:

$$
\mathrm{Nu}=\frac{0.026 \mathrm{D}^{0.8}}{\mathrm{k}}\left(\frac{\mathrm{C}_{\mathrm{P}} \mu^{0.2}}{\mathrm{P}_{\mathrm{r}}^{0.6}}\right)(\rho \nu)^{0.8}\left(\frac{\rho_{\mathrm{m}}}{\rho_{\mathrm{L}}}\right)\left(\frac{\mu_{\mathrm{m}}}{\mu_{\mathrm{c}}}\right)^{0.2}
$$

The subscript $m$ refers to properties evaluated at the arithmetic mean temperature of the local free-stream static temperature and wall temperature, $\rho_{L}$ is the local gas density of the free stream, $v$ is the local 
gas velocity, subscript $c$ refers to mean chamber temperature, and $k$ is the thermal conductivity of the gas.

In the present analysis, all the local values will be approximated by appropriate mean values.

\subsubsection{Radiative Heat Transfer}

The radiative emission in a combustion chamber is largely due to molecular rotational and interatomic vibrations of heteropolar gaseous molecules such as water vapor, carbon monoxide, carbon dioxide, hydrocarbons, amronia, and nitrogen oxides. Symmetrical molecules such as hydrogen, oxygen, and nitrogen show no appreciable emission bands in those wave regions important for chamber radiant heat transfer. In a heterogeneous mixture, such as bipropellant sprays, clouds of finelyspread disperse phases, such as soot particles of hydrocarbon-based propellant c mbustion, the radiation power could increase by a large factor of 2 to 10 times the equivalent homogeneous gas mixture.

The radiant heat transfer to the wall by the hot gas emission is given by

$$
\mathrm{q}_{\mathrm{R}}=\sigma A\left(\varepsilon_{\mathrm{g}} \mathrm{T}^{4}-\mathrm{a}_{\mathrm{W}} \mathrm{T}_{\mathrm{W}}^{4}\right)
$$

where $\varepsilon_{g}$ is the overall gas emissivity, and $a_{W}$ is the effective surface absorptivity of the wall. If the wall surface temperature $\mathrm{T}_{\mathrm{W}}$ is close to the gas temperature $T$, then $\alpha_{\mathrm{W}}$ approaches $\varepsilon_{\mathrm{g}}$. When $\mathrm{T}_{\mathrm{W}}$ and $\mathrm{T}$ are not too far apart, the following approximation may be used:

$$
\varepsilon_{g}=a_{W}=\varepsilon_{g a v}(4+a+b-c) / 4,
$$

where $\varepsilon_{g}$, av is the gas emissivity evaluated at the arithmetic mean temperature of $T$ and $T_{w}$, and the coefficients $a, b$, and $c$ are given by

$$
\begin{aligned}
& \mathrm{a}=\frac{\partial\left(\ln \varepsilon_{\mathrm{g}}\right)}{\partial\left(\ln \mathrm{P}_{\mathrm{g}} \mathrm{L}_{\mathrm{R}}\right)} \\
& \mathrm{b}=\frac{\partial\left(\ln \varepsilon_{\mathrm{g}}\right)}{\partial(\ln \mathrm{T})}
\end{aligned}
$$




$$
c=\frac{\partial\left(\ln a_{W}\right)}{\partial(\ln T)}+\frac{\partial\left(\ln \varepsilon_{g}\right)}{\partial(\ln T)}
$$

where $L_{R}$ is the radiation path length of the flame and $P_{g}$ is the gas pressure. Numerical data of the coefficients $a, b$, and $c$ for $\mathrm{CO}_{2}$ and $\mathrm{H}_{2} \mathrm{O}$ have been published by Hottel (1959).

In the present analysis, the numerical value of absorptivity, $a_{w}$, at the wall that appears in equation (4) can be taken to be different from the gas emissivity value $\varepsilon_{\mathrm{q}}$. This difference is incorporated in the definitions of the expression of $\beta$ which contains $\varepsilon$ and of $\beta_{w}$ which contains $a_{w}$. Further assumptions concerning the numerical values of $\varepsilon_{g}$ and $a_{w}$ are discussed in sections 3 and 4 .

\subsubsection{Performance Profile of the Combustion Process}

The method of application of the scaling law, equation (5), for the evaluation of combustor performance is described below.

\subsubsection{Non-Adiabatic and Adiabatic Chamber Temperature}

The non-dimensional chamber temperature $\theta_{C}$ is calculated from the scaling law for the prescribed engine design and operating parameters. By using equations (8) to (18), one can, in general, determine the values of $\alpha, \beta, \beta_{w}$, and $Q_{E}$ to estimate the numerical values of $K$ and $\gamma$ from equations (6) and (7). The dimensionless temperature $\theta_{C}$ is then calculated from equation (7) and plotted as a function of $\gamma$ and $\mathrm{K}$ (Fig. 2). The actual temperature $T_{C}$ is finally determined from equations (10) and (11).

The non-dimensional isothermal lines, i.e. constant value of ${ }^{\theta} \mathrm{C}$, are a family of straight lines that intersect the $\mathrm{K}$-coordinate at the chamber temperature $\theta_{C}$ (Fig. 2). Note that when $n_{h}=1.0$, the nondimensional temperature $\theta_{C}$ assumes the value of $1+\theta_{i}$ for any value of $\alpha$ and $\beta$. This value is equal to the "adiabatic flame temperature."

An examination of the asymptotic behavior of the scaling law at larger and smaller values of $\gamma$ reveals a rather interesting feature of the non-adiabatic flame temperature profiles. When $\gamma$ is much smaller than unity, and $K$ is close to a constant value, i.e., $\alpha$, $B$, and $\beta_{w} \ll 1$, the variation in the chamber temperature with respect 
ORIGINAL PAGE IS

OF POOR QUALITY

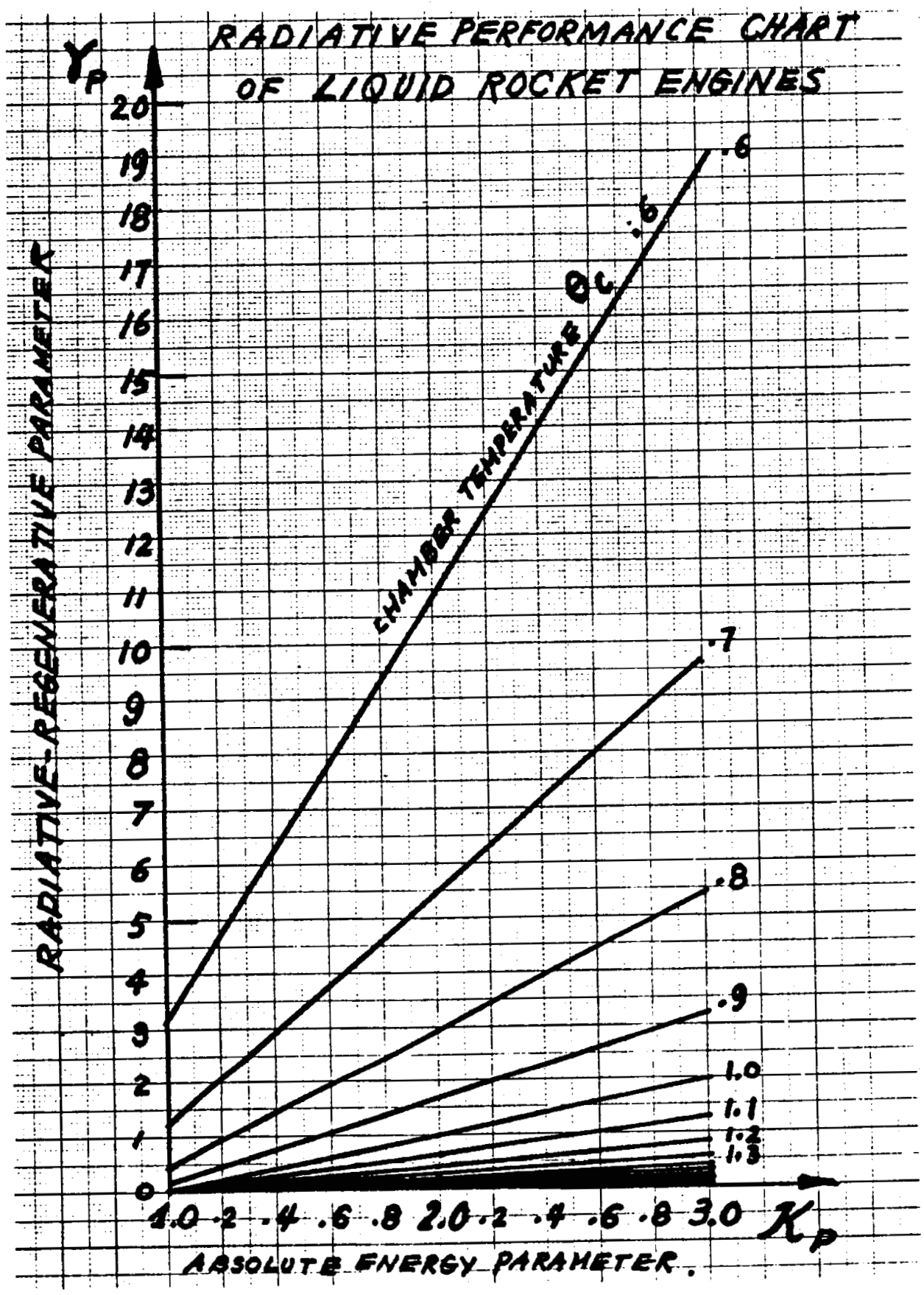

Fig. 2. Scaling Law of Liquid Rocket Combustion Chamber 
to the variations in the numerical values of $\gamma, \alpha, \beta$, and $\beta_{w}$ is negligibly small. This behavior is similar to what may be termed an "asymptotically adiabatic" pattern wherein the chamber temperature is close to the adlabatic flame temperature in the broad range of the values of $\alpha, \beta$, and $\beta_{w}$. Physically, the case corresponds to the rocket engines with a "high enthalpy throughput" in comparison to the combined radiative, conductive, and convective loss, so that the latter thermal energy loss hardly affects the chamber temperature. On the contrary, when the values of $\gamma$ are not small, the non-dimensional chamber temperature variation, associated with the variations in the values of $\alpha, \beta$, and $\beta_{w}$, is not negligibly small, i.e., the chamber temperature depends strongly on the loss mechanisms. This corresponds to those "low enthalpy throughput" engines in which the combined heat loss by radiation, conduction, and convection constitutes a significant fraction of the enthalpy flow rate through the engines.

\subsubsection{Engine Classification, High and Low Enthalpy Engines}

Two remarkably different chamber temperature characteristics at low $\gamma$ values $(\gamma \ll 1)$ corresponding to high enthalpy flow and high $\gamma(\gamma \leq 1)$ for low enthalpy flow, suggest unique classification of all the liquid rockets into high and low enthalpy engines. In order to illustrate this feature, Table 1 gives a set of data of the SSME and VTE used to estimate the values of $\gamma$ of each engine.

TABLE 1. VTE and SSME Data

\begin{tabular}{|c|c|c|c|c|c|}
\hline & & \multicolumn{2}{|c|}{ VTE } & \multicolumn{2}{|c|}{ SSME } \\
\hline \multirow[t]{2}{*}{ Combustor } & Diameter ( $f t$ ) & \multicolumn{2}{|c|}{0.204} & \multicolumn{2}{|c|}{1.40} \\
\hline & Length $(f t)$ & \multicolumn{2}{|c|}{0.333} & \multicolumn{2}{|c|}{0.67} \\
\hline \multirow[t]{8}{*}{ Propellants } & Propellant & $\begin{array}{l}\text { Monomethyl- } \\
\text { Hydrazine }\end{array}$ & $\begin{array}{l}\text { Nitrogen } \\
\text { Tetroxide }\end{array}$ & Hydrogen & Oxygen \\
\hline & State at inlet & Liquid & Liquid & Gas & Liquid \\
\hline & Bolling Point $\left({ }^{\circ} R\right)$ & 649 & 530 & 36.9 & 163 \\
\hline & $\begin{array}{l}\text { Heat of vapori ation } \\
(\text { Btu/1b) }\end{array}$ & 377 & 178 & 190 & 85 \\
\hline & $\begin{array}{l}\text { Specific heat } \\
\left(\mathrm{Btu} / 1 \mathrm{~b}{ }^{\circ} \mathrm{R}\right)\end{array}$ & 0.7 & 0.378 & 3.75 & 0.5 \\
\hline & $\begin{array}{l}\text { Mass flow rate } \\
(1 \mathrm{~b} / \mathrm{sec})\end{array}$ & 0.177 & 0.2932 & 150 & 900 \\
\hline & $\begin{array}{l}\text { Inlet temperature } \\
\left({ }^{\circ} \mathrm{R}\right)\end{array}$ & 460 & 460 & 500 & 163 \\
\hline & $\begin{array}{l}\text { Heat of combustion } \\
\text { (Btu/1b) }\end{array}$ & \multicolumn{2}{|c|}{8910} & \multicolumn{2}{|c|}{11250} \\
\hline \multirow{2}{*}{$\begin{array}{l}\text { Scaling } \\
\text { Parameter }\end{array}$} & $\gamma$ & \multicolumn{2}{|c|}{$10^{-3} \approx 1 *$} & \multicolumn{2}{|c|}{$10^{-5} \approx 10^{-3 *}$} \\
\hline & $\mathrm{K}$ & \multicolumn{2}{|c|}{$1.02 \sim 1.07$} & \multicolumn{2}{|c|}{$1.03 \sim 1.04$} \\
\hline
\end{tabular}


In Table 1, the values of $\gamma$ for the SSME are much smaller than those of the VTE by an order of magnitude of $10^{-2}$ to $10^{-3}$. This is primarily caused by the significant difference in the total mass $f$ low rate of the SSME, 1.e., $\dot{\mathrm{m}}_{\mathrm{F}}+\dot{\mathrm{m}}_{\mathrm{o}}=1050 \mathrm{lb} / \mathrm{sec}$, and the flow rate for the VTE which is $0.470 \mathrm{1b} / \mathrm{sec}$. The latter value amounts to only 0.047 percent of the SSME.

The consequence of the difference in $\gamma$ values is the dramatic difference in the chamber temperature. As a rule of thumb, the chamber temperature reduction in high enthalpy engines with $\gamma \simeq 10^{-3}$, is of the order of "a degree," and that in low enthalpy engines with $\gamma \cong 10^{-1}$ is of the order of $\sim 10^{2}$ to $10^{3}$ degrees. The detailed chamber temperature loss in the SSME and the VTE is discussed at length in Section 4. 


\section{PROPELLANT DROPLET VAPORIZATION AND COMBUSTION IN THE RADIATION ENVIRONMENT OF A COMBUSTION CHAMBER}

The effects of the radiation enhancement on the propellant vaporization, combustion, overall combustion efficiency, and, subsequently, the chamber temperature, are included in the scaling law using the radiation modulated efficiencies $\eta_{C R}$, $\eta_{F V R}$, and $\eta_{O V R}$. However, the values of these efficiencies can presently only be estimated because of the lack of analytical or experimental data and formulas that interrelate the values of these efficiencies with a combustor design and operating condition.

The basic steps required in the determination of these efficiencies are (1) the acquisition of the droplet laws that account for the radiation enhanced vaporization and combustion, and (2) the prediction of the detailed spray combustion field by a comprehensive CFD code that incorporates the radiation modulated droplet laws. In this section, the first step extends the classical single droplet theory (Williams, 1985) and the second step describes an ad-hoc physical model that interrelates the overall combustion and vaporization efficiencies with the single droplet laws obtained in step 1.

The proposed mode1 of radiation-enhanced droplet vaporization and combustion laws is developed on the basis of the classical single droplet theory with the following additional features. The radiation environment is isotropic and the gas is assumed to be a gray medium. The droplet has a constant absorptivity and the radiative transfer is in radiative nonequilibrium. The state of non-equilibrium radiative heat transfer will therefore require the treatment of the combined radiation-conduction convection mechanism via the solution of radiative transfer equation coupled with the conservation laws of mass, momentum, and energy of the participating gas flow field.

\subsection{Mathematical Formulation}

The conservation laws governing the droplet processes (Fig. 3) are given by

$$
\frac{1}{r^{2}} \frac{d}{d r}\left(r^{2} \psi_{k}\right)=B_{k} w \quad k=m, o, F, T
$$

where

$$
\psi_{\mathrm{m}}=\rho \nu \quad \mathrm{j}=\mathrm{F} \quad \text { Fuel }
$$


ORIGINAL PAGE IS

OF POOR QUALITY

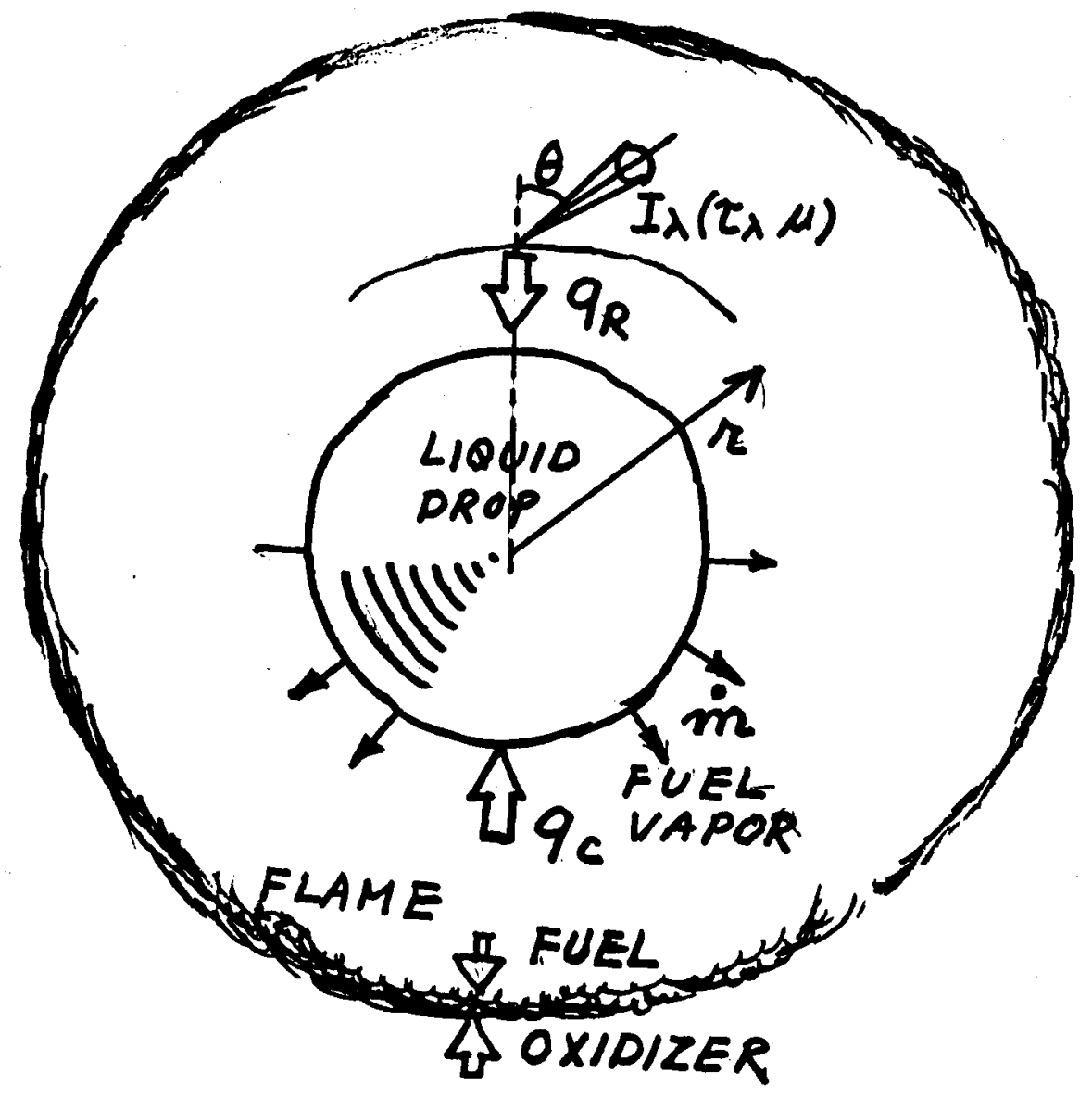

Fig. 3. Single Droplet Combustion in Radiative Environment 


$$
\begin{aligned}
& \psi_{j}=\psi_{m} \alpha_{j}-\rho D \frac{d \alpha_{j}}{d r} \quad j=0 \quad \text { oxidizer } \\
& \psi_{T}=\psi_{m} \alpha_{T}-\frac{\lambda}{c_{P}} \frac{d \alpha_{T}}{d r}+q_{R}
\end{aligned}
$$

in which $\rho$ is the gas density, $\nu$ is the gas mixture velocity, $D$ and $\lambda$ are mass diffusivity and thermal conductivity of the gas mixture, respectively, $c_{P}$ is the gas specific heat at constant pressure, and $q_{R}$ is the radiative heat flux, $\alpha_{j}$ and $\alpha_{T}$ are Schvab-Zeldovich variables defined by

$$
\begin{aligned}
& \alpha_{j}=\frac{y_{j}}{\left(v_{j}{ }^{1}-v_{j}{ }^{\prime} w_{j}\right.} \\
& \alpha_{T}=\frac{\int_{T_{h}}^{T} C_{P} d_{T}}{q o} \\
& q_{R}=\frac{Q_{R}}{q_{0}}
\end{aligned}
$$

where $y_{j}$ is the mass concentration, $w_{j}$ is the molecular weight of the $j$ th gaseous species, and $\nu_{j}$ " and $\nu_{j}^{\prime}$ are the stoichiometric coefficients which appear in the one-step reaction process described as follows:

$$
\sum_{j} v_{j}^{\prime} m_{j}=\sum_{j} v_{j}^{\prime \prime} m_{j}
$$

and $\mathrm{q}^{\circ}$ is the heat of combustion

$$
q^{o}=\sum h_{i}^{0} w_{i}\left(v_{i}^{\prime}-v_{i}^{\prime \prime}\right)
$$

in which $h_{i}{ }^{\circ}$ is the standard heat of formation per unit mass for species $i$ at reference temperature. $Q_{R}$ and $q_{R}$ are the dimensional and nondimensional heat fluxes, respectively. 
The radiative heat $f$ lux $Q_{R}$ is given in terms of the radiation intensity $I_{\lambda}$ as follows

$$
Q_{R}=2 \pi \int_{0}^{\infty} \int_{-1}^{1} \mu I_{\lambda}\left(\tau_{\lambda}, \mu\right) d \mu d \lambda
$$

and $I_{\lambda}$ is governed by the following radiative transfer equation

$\mu \frac{\partial I_{\lambda}}{\partial \tau_{\lambda}}+\frac{\left(1-\mu^{2}\right) \partial I_{\lambda}}{\tau \lambda}+I_{\lambda}=\left(1-w_{\lambda}\right) I_{b \lambda}+\frac{{ }^{w}}{2} \int_{-1}^{1} I_{\lambda}(\tau, \mu \mu) d \Omega$

Here $\tau_{\lambda}$ is the optical thickness, $\Omega$ is the solid angle exterided by a surface relative to an observer, $\lambda$ is the wave length, $\mu$ is the $\cos \theta$ with $\theta$ being equal to the angle extended by the position vector in radial direction, and that of the radiation beam. The terms $a_{\lambda}, \delta_{\lambda}$, and $\beta_{\lambda}$ are absorption, scattering, and extinction coefficients, respectively. $\beta_{\lambda}$ and $w_{\lambda}$ are given by the following expressions

$$
\begin{aligned}
& { }_{\lambda}=a_{\lambda}+\sigma_{\lambda} \\
& { }^{w_{\lambda}}=\sigma_{\lambda} / \beta_{\lambda} .
\end{aligned}
$$

The subscript $b$ appearing in the radiation intensity $I_{b \lambda}$ refers to that of black body radiation.

The boundary conditions of the present problem are (1) an impermeable droplet surface with respect to oxidizer and combustion product, (2) the balance of the combined radiation and conductive heat transfer with the latent heat of vaporizing species leaving the droplet, (3) intensities of radiation on the droplet surface and at the gaseous environment at $r+\infty$, and (4) the temperature and concentration of species at $r+\infty$. These conditions are summarized in the following:

$$
\begin{aligned}
r= & r_{\ell}: \\
& {\left[\rho \nu\left(\begin{array}{c}
y_{o} \\
y_{P}
\end{array}\right)-\rho D \frac{d}{a_{r}}\left(\begin{array}{c}
y_{o} \\
y_{P}
\end{array}\right)\right]_{r_{\ell}}=0 }
\end{aligned}
$$




$$
\begin{aligned}
& 4 \pi r_{\ell}^{2}\left(\frac{d T}{d r}-Q_{R}\right)_{r_{\ell}}=\dot{m} L \\
& I\left(r_{\ell, \mu)}=\frac{n^{2} \sigma T_{b}^{4}}{\pi}\right. \\
& r \rightarrow \infty: \\
& T=T_{\infty}, \quad Y_{i}=Y_{i \infty} \\
& I(\infty, \mu)=\frac{n^{2} \sigma T^{4}}{\pi} .
\end{aligned}
$$

3.2 Radiation-Enhanced Vaporization, Burning Laws and Flame Location

By following the mathematical procedure adopted in the classical single droplet theory, one can predict the vaporization or burning rate as the characteristic values of the two-point boundary value problems.

The results of the analysis are listed in the following:

(1) For a vaporizing droplet, the vaporization rate $\dot{\mathrm{m}}_{\mathrm{VR}}$ is calculated in terms of the "radiation-enhanced vaporization transfer number," $\mathrm{B}_{\mathrm{VR}}$, as follows

$$
\begin{aligned}
\dot{\mathrm{m}}_{\mathrm{VR}} & =4 \pi \rho \mathrm{D} \mathrm{r}_{\ell} \ln \left(1+\mathrm{B}_{\mathrm{VR}}\right) \\
\mathrm{B}_{\mathrm{VR}} & =\frac{\int_{\mathrm{T}_{\mathrm{L}}}^{\mathrm{T}} \mathrm{C}_{\mathrm{P}} \mathrm{dT}}{\mathrm{L}}-\frac{\dot{\mathrm{m}}^{\circ}}{4 \pi(\rho \mathrm{D})^{2} \mathrm{~L}} \int_{0}^{\xi_{\ell}} \mathrm{q}_{\mathrm{R}}\left(\xi^{\prime}\right) \xi^{\prime 2} \mathrm{e}^{\xi^{\prime} \mathrm{d} \xi^{\prime}}
\end{aligned}
$$

where

$$
\xi=\dot{\mathrm{m}} \int_{0}^{\mathrm{r}} \frac{\mathrm{dr}}{4 \pi \rho \mathrm{D} \mathrm{r}^{2}} \text {. }
$$

(2) For a combusting droplet, the burning rate and the flame location $r_{f}$ are predicted to be 


$$
\stackrel{\dot{\mathrm{n}}}{\mathrm{CR}}=4 \pi \rho \mathrm{D} \mathrm{r}_{\ell} \ln \left(1+\mathrm{B}_{\mathrm{CR}}\right)
$$

and

$$
\frac{\mathrm{r}_{f}}{\mathrm{r}_{\ell}}=\frac{\ln \left(1+\mathrm{B}_{C R}\right)}{\ln \left(1+\frac{\mathrm{W}_{\mathrm{F}} \nu_{\mathrm{F}}}{\mathrm{W}_{\mathrm{O}} \nu_{\mathrm{O}}} \mathrm{Y}_{\mathrm{o}}\right)}
$$

where the radiation-enhanced combustion transfer number, ${ }^{B}{ }_{C R}$, is expressed by

$B_{C R}=\left[\int_{T_{b}}^{T} C_{P} d T+\frac{q^{o} y_{o}}{w_{o} \nu_{o}}-\frac{\dot{m} q^{o}}{4 \pi(\rho D)^{2}} \int_{0}^{\xi l} q_{R}\left(\xi^{\prime}\right) \xi^{\prime 2} e^{\xi^{\prime}} d \xi\right] / L$.

Note that when the temperature of the environment is higher than that of the droplet surface, the radiative heat flux points toward the droplet, thus, the $\mathrm{q}_{R}$ has a negative value. Under such circumstances, equations (35) and (39) show that the transfer numbers $b_{V R}$ and $B_{C R}$ are larger than the values determined for the cases when the radiation is absent.

A special case in which $q_{R} r^{2}=$ constant, equations (34) and (35), reduce to the following form:

$$
\mathrm{n}_{\mathrm{VR}} \text { or } \mathrm{CR}=4 \pi \rho \mathrm{D} \mathrm{r}_{\ell} \ln \left(1+\mathrm{B}_{\mathrm{VR}} \text { or } \mathrm{CR}\right)
$$

where

$$
\mathrm{B}_{\mathrm{VR}}=\frac{\mathrm{B}_{\mathrm{V}}}{1-\left(\mathrm{Q}_{\mathrm{R}} * / \dot{\mathrm{m} L}\right)}
$$

and

$$
{ }^{B}{ }_{C R}=\frac{{ }_{C}}{1-\left(Q_{R}^{* / \dot{m} L}\right)} \text {. }
$$


Here $Q_{R}{ }^{*}$ is the rate of the radiative heat transfer to the droplet surface, i.e.,

$$
Q_{R}^{*}=4 \pi r_{\ell}^{2} Q_{R}\left(r=r_{\ell}\right)
$$

Thus, the enhancement of the vaporization or combustion of a droplet can be expressed by the transfer number factor given by

$$
\varepsilon_{R}=\frac{{ }_{V R}}{B_{V}}=\frac{{ }_{C R}}{{ }_{C} C}=\frac{1}{1-\left(Q_{R} * / \dot{m} \mathrm{~L}\right)}
$$

where $\varepsilon_{R}$ is greater than unity.

An alternative expression that describes the vaporization and combustion enhancement is to use the radiation factor $\eta_{R}$ defined by

$$
\frac{\mathrm{Q}_{\mathrm{R}} *}{\dot{\mathrm{m} L}}=\frac{n_{\mathrm{R}} \int_{\mathrm{T}_{\mathrm{b}}}^{\mathrm{T}} \mathrm{C}_{\mathrm{P}} \mathrm{dT}}{\mathrm{L}}
$$

The vaporization rate can be expressed in terms of the radiation factor $\eta_{R}$ as

$$
\dot{\mathrm{m}}_{\mathrm{VR}}=4 \pi \rho \mathrm{D} \mathrm{r}_{\ell} \ln \left[1+\frac{\int_{\mathrm{T}_{\mathrm{b}}}^{\mathrm{T}} \mathrm{C}_{\mathrm{P}} \mathrm{dT} / \mathrm{L}}{1-\mathrm{n}_{\mathrm{R}}\left(\int_{\mathrm{T}_{\mathrm{b}}}^{\mathrm{T}} \mathrm{C}_{\mathrm{P}} \mathrm{dT} / \mathrm{L}\right)}\right] \text {. }
$$

The droplet vaporization and combustion radiation enhancement factors $\mathrm{C}_{\mathrm{VR}}$ and $\mathrm{C}_{\mathrm{CR}}$ can be defined as the ratio of the vaporization and combustion rates as follows:

$$
\mathrm{C}_{\mathrm{VR}}=\frac{\dot{\mathrm{m}}_{\mathrm{VR}}}{\dot{\mathrm{m}}_{\mathrm{V}}}
$$




$$
\mathrm{C}_{\mathrm{CR}}=\frac{\stackrel{\mathrm{m}}{\mathrm{CR}}_{\dot{\mathrm{m}}_{\mathrm{C}}}}{{ }^{\mathrm{n}}}
$$

where $\dot{\mathrm{m}}_{\mathrm{V}}$ and $\dot{\mathrm{m}}_{\mathrm{C}}$ are the vaporization and combustion rate for the same environment conditions at $r \rightarrow \infty$, but in the absence of radiative effects on the droplet rate processes.

\subsection{Radiation F1ux and Intensity}

The dimensionless radiation heat flux $\mathrm{q}_{R}$ appearing in the vaporization and combustion rates, equations (34), (35), (37), and (39), is a function of the intensity of radiation $I_{\lambda}$, equation (27). Thus, the determination of the heat flux requires the knowledge of the solution of equation (28).

According to the assumption of a gray gas and an isotropic scattering, the solution of the radiative transfer equation can be expressed in the following power series solution involving Legendre functions

$$
I(\tau, \mu)=\sum_{m=0}^{\infty} \frac{2 m+1}{4 \pi} P_{m}(\mu) \psi_{m}(\tau)
$$

where $\mu=\cos \theta$. By substituting equation (49) into equation (28), which is specialized to the gray gas approximation, and by equating the coefficient appearing in each order of the Legendre function, one obtains the following set of equations:

$$
\begin{gathered}
\mathrm{m}=0 ; \frac{\mathrm{d} \psi_{1}}{\mathrm{~d} \tau}+2 \frac{\psi_{1}}{\tau}+(1-\mathrm{w}) \psi_{0}=4 \pi(1-\mathrm{w}) \mathrm{I}_{\mathrm{b}}-\frac{1}{2} \mathrm{w} \psi_{2} \\
\mathrm{~m}=1 ; 2 \frac{\mathrm{d} \dot{\psi}_{2}}{\mathrm{~d} \tau}+6 \frac{\psi_{2}}{\tau}+\frac{\mathrm{d} \psi_{6}}{\mathrm{~d} \tau}+3 \psi_{1}=0 \\
\mathrm{~m}=\mathrm{n} ; \quad(\mathrm{n}+1)\left[\frac{\mathrm{d} \psi_{\mathrm{n}+1}}{\mathrm{~d} \tau}+(\mathrm{n}+2) \frac{\psi_{\mathrm{n}+1}}{\tau}\right]+(2 \mathrm{n}+1) \psi_{\mathrm{n}} \\
+\mathrm{n}\left[\frac{\mathrm{d} \psi_{\mathrm{n}-1}}{\mathrm{~d} \tau}-(\mathrm{n}-1) \frac{\psi_{\mathrm{n}-1}}{\tau}\right]=0 .
\end{gathered}
$$


The net radiation $f$ lux $\mathrm{q}_{R}$ * and incident radiation $G$ can be expressed in terms of the integral as follows:

$$
\begin{aligned}
& q_{R} *=2 \pi \int_{-1}^{1} \mu I(\tau, \mu) d u \cong \psi_{1} \\
& G *=2 \pi \int_{-1}^{1} I(\tau, \mu) d u \cong \psi_{0}
\end{aligned}
$$

where the first two terms $\psi_{0}$ and $\psi_{1}$ appearing in equation (49) are chosen to construct the heat $\operatorname{flux} \mathrm{q}_{\mathrm{R}}$ and incident radiation $\mathrm{G}^{*}$.

Upon substituting equations (53) and (54), one obtains the following equations governing $\mathrm{q}_{\mathrm{R}}$ :

$$
\frac{\mathrm{d}^{2} \mathrm{q}_{\mathrm{R}}^{*}}{\mathrm{~d} \tau^{2}}+\frac{2}{\tau} \frac{\mathrm{d} \cdot \mathrm{q}_{\mathrm{R}}^{*}}{\mathrm{~d} \tau}-\left[3(1-\mathrm{w})+\frac{2}{\tau^{2}}\right] \mathrm{q}_{\mathrm{R}}^{*}=4 \pi(1-\mathrm{w}) \frac{\mathrm{d} \mathrm{I}_{\mathrm{b}}}{\mathrm{d \tau}}
$$

and

$$
\mathrm{q}_{\mathrm{R}}^{*}=-\frac{1}{3} \frac{\mathrm{d} \mathrm{G} *}{\mathrm{~d} \tau}
$$

In general, equation (55) must be solved in conjunction with the conservation equations (18) together with the boundary conditions, equations (31) and (33). Such general solutions can be expressed by a standard procedure, and details of such cases will be reported in the future.

The remaining part of this section will be devoted to a special case in which the absorptivity of the gas is virtually zero. This is the case of practical interest when the gas is optically thin.

By putting $w$ to be equal to unity, one finds that the solution satisfying equation (55) and the boundary conditions, equations (31) and (33), is given by: 


$$
\mathrm{q}_{\mathrm{R}} *=\frac{4 \mathrm{n}^{2} \sigma \mathrm{r}_{\ell}}{3 \beta \mathrm{r}^{2}}\left(\frac{\mathrm{T}^{4}-\mathrm{T}_{\mathrm{p}}^{4}}{\frac{1}{\sqrt{3} \beta \mathrm{r}_{\ell}}}\right)
$$

and

$$
Q_{R}=\frac{16 \pi \sigma n^{2} r_{\ell}}{3 \beta}\left(\frac{T^{4}-T_{b}^{4}}{1-\frac{1}{\sqrt{3} \beta r_{\ell}}}\right) \text {. }
$$

The above expression, equation (58), can be substituted into equations (44), (47), and (48) to predict the transfer number enhancement factors, $\varepsilon_{R}, C_{V R}$, and $C_{C R}$, as well as the radiation factor, equation (45). 


\section{PERFORMANCE ANALYSIS OF SELECTED LIQUID ROCKET ENGINES}

A numerical analysis for the SSME and VTE has been conducted to compare the performance characteristics of high and low enthalpy engines and to assess the need of regeneration of the heat transported to the chamber wa11 of each engine.

In order to achieve the objectives, the sensitivity of each engine on the following factors is considered: (1) engine size, (2) Nusselt number, (3) emissivity, (4) regenerative efficiency, and (5) power level.

The following two sets of assumptions are adopted as the reference for the performance comparison:

(1) The overall vaporization efficiencies of bipropellants and the overal1 combustion efficiency, in the absence of radiation, are given by

$$
\begin{aligned}
& \text { VTE : } \eta_{V F}=0.94 \quad \eta_{V O}=0.95 \text { and } \quad n_{C}=0.92 \text {. } \\
& \text { SSME : } \eta_{\mathrm{VF}}=0.95 \quad \eta_{\mathrm{VO}}=0.9 \quad \text { and } \quad \eta_{\mathrm{C}}=0.92 \text {. }
\end{aligned}
$$

(2) The overall vaporization efficiencies for fuel and oxidizer droplets and the global combustion efficiency in the liquid rocket engine combustion chamber are given by

$$
\begin{aligned}
& n_{V F R}=\frac{\dot{\mathrm{m}}_{\mathrm{VFR}}}{\dot{\mathrm{m}}_{\mathrm{VF}}} n_{\mathrm{VF}}=c_{\mathrm{VFR}} n_{\mathrm{VF}} \\
& n_{\mathrm{VOR}}=\frac{\dot{\mathrm{m}}_{\mathrm{VOR}}}{\dot{\mathrm{m}}_{\mathrm{VO}}} n_{\mathrm{VO}}=\mathrm{c}_{\mathrm{VOR}} n_{\mathrm{VO}}
\end{aligned}
$$

where $C_{V F R}$ and $C_{V O R}$ are obtained from equations (47) and (48), respectively. These relationships are consistent with the classical criterion of liquid rocket engine design advocated by Priem (1958). For example, $\mathrm{C}_{\mathrm{VR}}$ 's are determined by

$$
\mathrm{C}_{\mathrm{VR}}=\frac{\ln \left\{\frac{1+\left(1-\mathrm{n}_{\mathrm{R}}\right)\left[\mathrm{C}_{\mathrm{P}}\left(\mathrm{T}_{\mathrm{m}}-\mathrm{T}_{\mathrm{b}}\right) / \mathrm{L}\right]}{1-\left[\mathrm{n}_{\mathrm{R}} \mathrm{C}_{\mathrm{P}}\left(\mathrm{T}_{\mathrm{m}}-\mathrm{T}_{\mathrm{b}}\right) / \mathrm{L}\right.}\right\}}{\ln \left[1+\frac{\mathrm{C}_{\mathrm{P}}\left(\mathrm{T}_{\mathrm{m}}-\mathrm{T}_{\mathrm{B}}\right)}{\mathrm{L}}\right]}
$$


The mean gas temperature, appearing in equation (61), is approximated by

$$
\mathrm{T}_{\mathrm{m}}=\frac{1}{2}\left(\zeta_{\mathrm{c}} \mathrm{T}_{\mathrm{c}}+\zeta_{\mathrm{w}} \mathrm{T}_{\mathrm{w}}\right)
$$

In which $\zeta_{c}$ and $\zeta_{\mathrm{w}}$ are the weighing factors, respectively, depending on the structure of bipropellant combustion (Chiu, 1986a, 1986b). For example, large group flame emission is largely responsible for the heat transfer to the wall and to the upstream regions to enhance droplet vaporization. Envelope flames of individual droplets and droplet clusters serve to self-accelerate the gasification process. In the latter cases, the numerical value of $\zeta_{c}$ of equation (62) is close to 2 and $\zeta_{w}$ is zero. Vaporizing droplets or clouds near the wall will have $\zeta_{\mathrm{w}}$ values close to 2 and $\zeta_{c}$ close to zero. The nature of the distributions of the group flame and drop or cluster bound flames strongly depends on the injection characteristics, droplet mixing pattern, and various spray-turbulent interaction processes. In view of this complex mechanism and the lack of experimental data or numerical simulation at the present time, the average values of $\zeta_{c}$ and $\zeta_{w}$ will be taken to be unity, i.e.,

$$
\mathrm{T}_{\mathrm{m}}=\frac{1}{2}\left(\mathrm{~T}_{\mathrm{c}}+\mathrm{T}_{\mathrm{w}}\right)
$$

\subsection{Results and Discussion}

The scaling laws and gasification rate models are used to develop a numerical algorithm (see Appendix A), to aid in the systematic numerical prediction of the chamber temperature as a function of chamber design and operating conditions. Basic engine data are listed in Table 1.

\subsubsection{Effects of Chamber Geometry}

Since the radiative heat loss is approximately linearly proportional to the chamber volume, whereas the conductive heat loss increases linearly with respect to the chamber surface area, the characteristics of chamber temperature loss with respect to the geometry are investigated. Figure 4 shows that the increase in the effective length and diameter of the VTE combustion chamber reduces the chamber temperature appreciably. Note that the maximum loss occurs at the highest gas emissivity, i.e., $\varepsilon_{g}=1.0$ and $n_{n}=0$. The maximum loss in a prototype engine is approximately $100^{\circ} \mathrm{R}$. However, when the effective length is increased by 10 times the real combustion value, i.e., $L_{\text {eff }}=3.33 \mathrm{ft}$, the maximum temperature 
ORIGINAL PAGE IS

OF POOR QUALITY

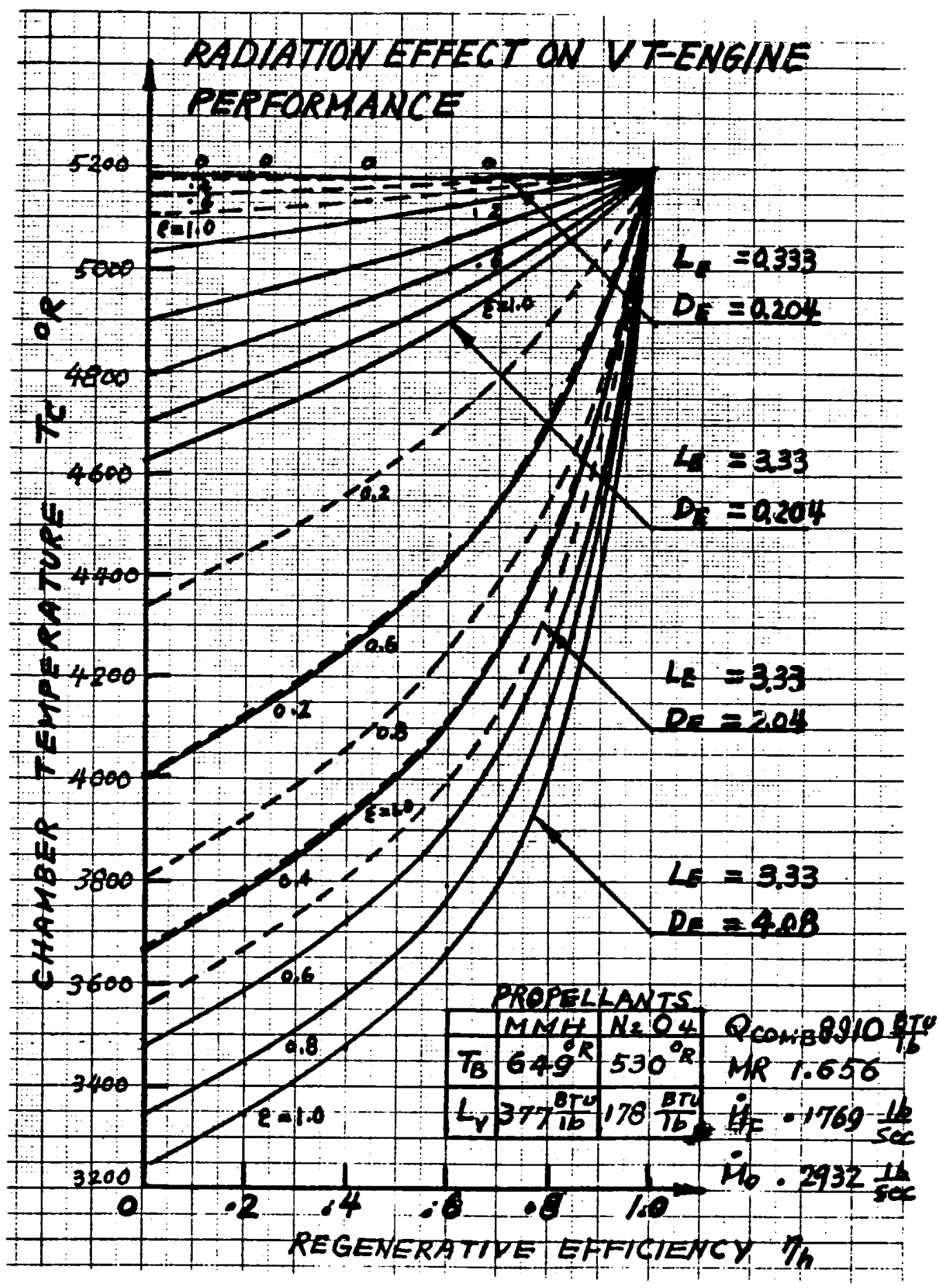

Fig. 4. Radiation Effect on the Performance of the VTE and Additional Hypothetical Sizes 
reduction is approximately $600^{\circ} \mathrm{R}$. The ratio of the radiative loss to the conductive heat loss is approximately 2 to 1 .

In contrast to the VTE, the chamber temperature reduction in SSME is negligibly small. For example, the maximum chamber tempcrature reduction in a prototype engine, with the emissivity being equal to unity and a vanishing regenerative efficiency, amounts to a few degrees. This is in sharp contrast to VTE with a temperature reduction of $100^{\circ} \mathrm{R}$ as previously described. Figure 5 shows that the maximum temperature drop of $150^{\circ} \mathrm{R}$ could occur in a hypothetical SSME engine that has a 200 times larger chamber volume than the prototype.

These significantly different chamber temperature loss characteristics of the VTE and SSME are attributed to the low and high enthalpy flow characteristics of each engine.

Figure 6 shows the ranges of the variations of $\gamma$ and $K$ for two types of engines, the VTE and the SSME. Note that the variations in the values of $\gamma$ for the SSME range from $10^{-5}$ to $10^{-3}$, and $\mathrm{K}$ remains nearly constant as the engine size increases. Note that the values of $\gamma$ in the VTE are approximately 100 times greater than that of the SSME and a pronounced variation in $K$ value occurs when the engine size increases. The latter factor has a small positive effect for minimizing the chamber temperature reduction.

The results shown above and in the remaining part of this section suggest that the low-enthalpy engines could have a relatively large temperature drop due to radiative heat loss. The regenerative scheme will be effective in particular when such engines are designed or being operated in marginal conditions such as lower power level flight.

\subsubsection{Effects of Nusselt Number}

The relative importance of the conductive-convective heat loss to that of radiation is assessed by comparing the chamber temperature variations in a range of Nusselt number extending from an order of unity to $10^{3}$. Figure 7 shows that the variation in $T_{C}$ for the VTE is relatively small in the range of $1<\mathrm{N}_{\mathrm{u}}<10^{2}$. A significant conductiveconvective loss occurs when $\mathrm{N}_{\mathrm{u}}$ exceeds a critical value of approximately

300. The presence of such a critical Nusselt number suggests that the low-enthalpy engines, such as the VTE, may be further classified into the "radiation loss dominated engine" when $\mathrm{N}_{\mathrm{u}}$ is smaller than the critical value and "conduction-convection loss dominated engine" if $\mathrm{N}_{\mathrm{u}}$ is greater than the critical value. 


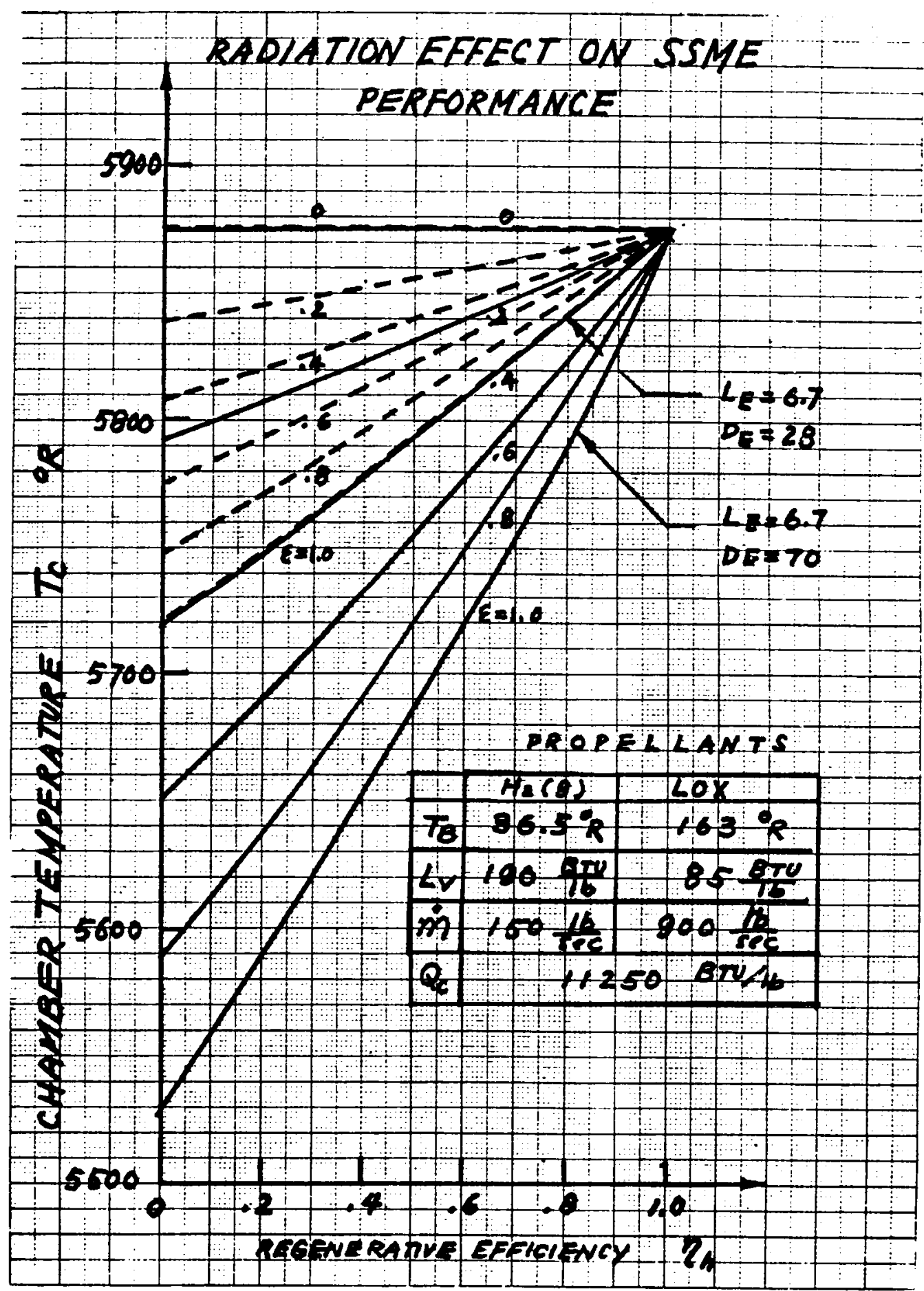

Fig. 5. Radiation Effects on the Performance of the SSME and Additional Hypothetical Sizes 
ORIGINAL PAGE IS

OF POOR QUALITY

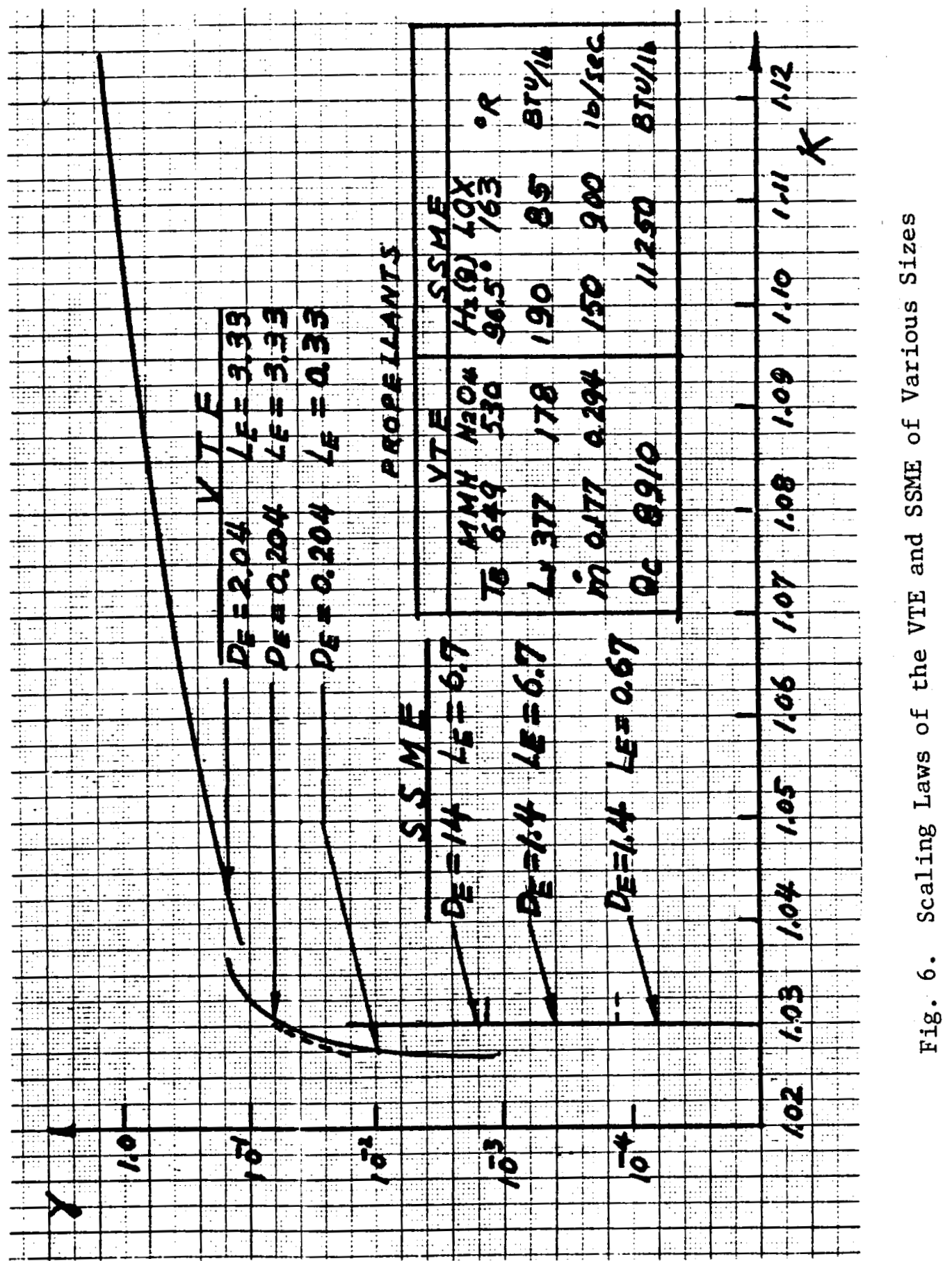


ORIGINAL PAGE IS

OF POOR QUALITY

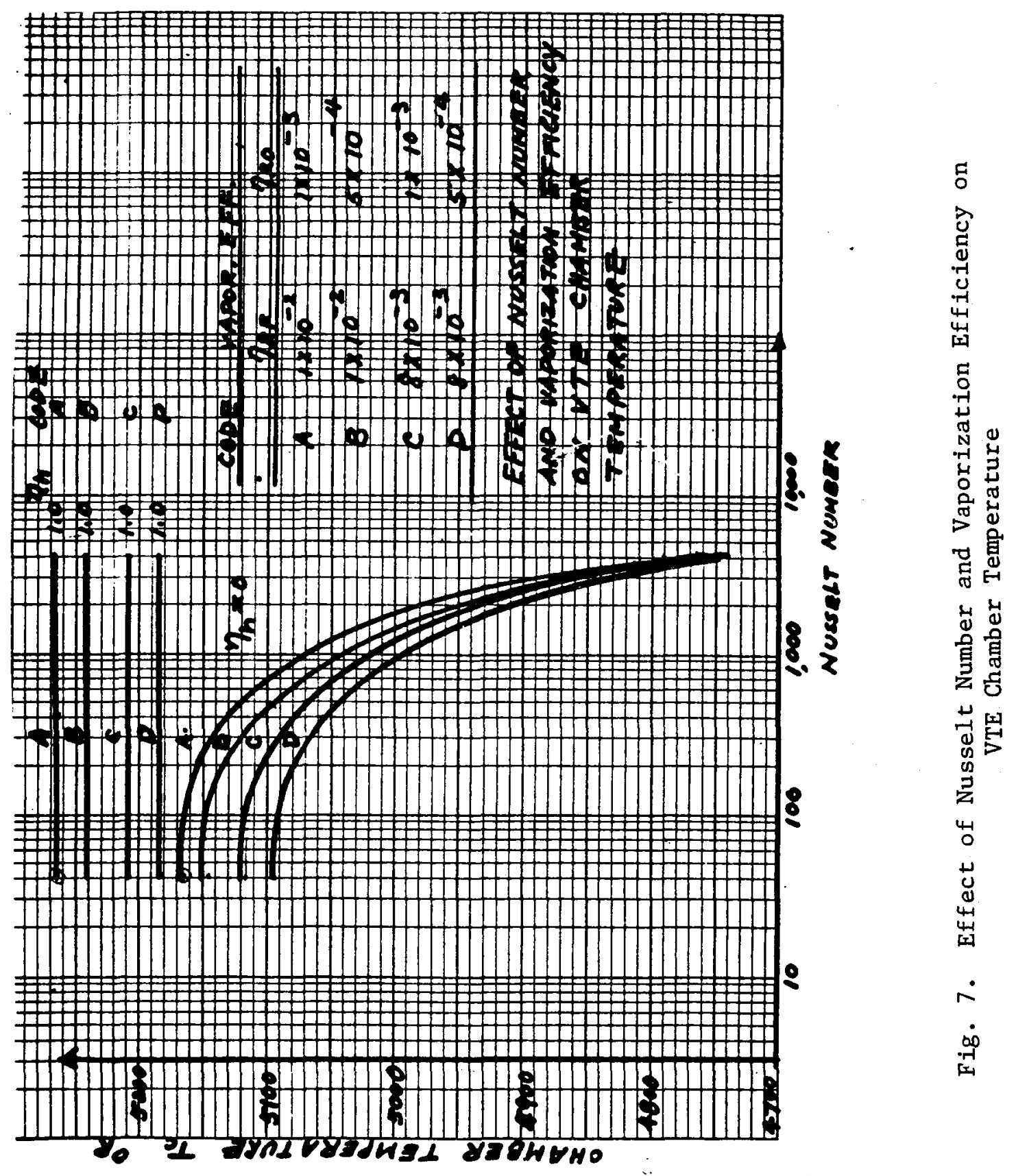


In contrast to the VTE, the chamber temperature losses estimated for the SSME in the same range of Nusselt numbers are found to be negligibly smal1 (Fig. 8).

\subsubsection{Effects of Radiation-Enhanced Combustion and Vaporization Rates}

The effects of radiation of the propellant gasification enhancement in the SSME is shown in Figure 9. Note that an almost $150^{\circ} \mathrm{R}$ gain in the chamber temperature is achieved in an adiabatic flame temperature case when $\eta_{R O}$ is increased from $5 \times 10^{-4}$ to $2 \times 10^{-3}$. The gain in chamber temperature at various degrees of regeneration is approximately $150^{\circ} \mathrm{R}$ for the prescribed increase in $\eta_{\mathrm{RO}}$. Figures 7 and 8 also show the general feature of the chamber temperature gain in the range of the Nusselt numbers considered.

This general temperature gain characteristic is attributed to the fact that the vaporization enhancement rate is approximately proportional to the enthalpy flows and, thus, constitutes a significant fraction of energy addition into the combustion process.

Thus, for both high- and low-enthalpy engines, the stretegy is to use as much radiation energy as possible to enhance the gasification process and the associated combustion efficiency while minimizing the radiative transfer loss to the wall.

\subsubsection{Effects of Engine Power Leve1}

Since the throttling of the engine power output is accomplished, in general, by the reduction in total enthalpy flow, the lower power level operation will exhibit low enthalpy characteristics; i.t., high $\gamma$ engine behavior. Figure 10 shows the VTE chamber temperature variations in the ranges of power level and gas emissivity between 0 to 1.0 . The effects of the Nusselt number, the power leve1 and gas emissivity on the chamber temperature are shown in Figure 11.

The results once again suggest that a dramatic reduction in chamber temperature, on the order of a few to several hundred degrees, is expected in low enthalpy engines. 


$$
\begin{aligned}
& \text { ORIGNAL PAGE IS } \\
& \text { OF POS F }
\end{aligned}
$$

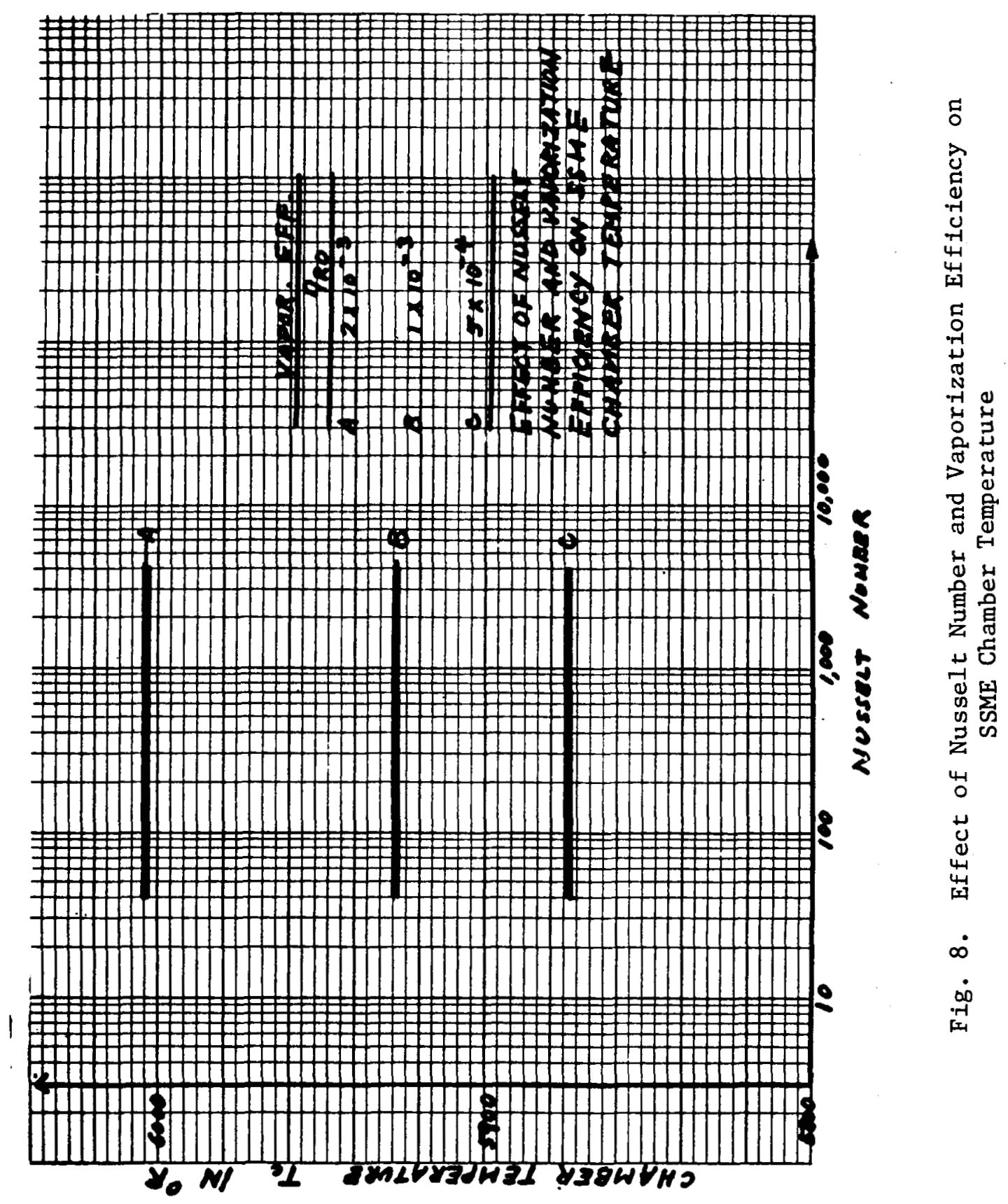


ORIGINIAL PAGE IS

OF POOR QUALITY

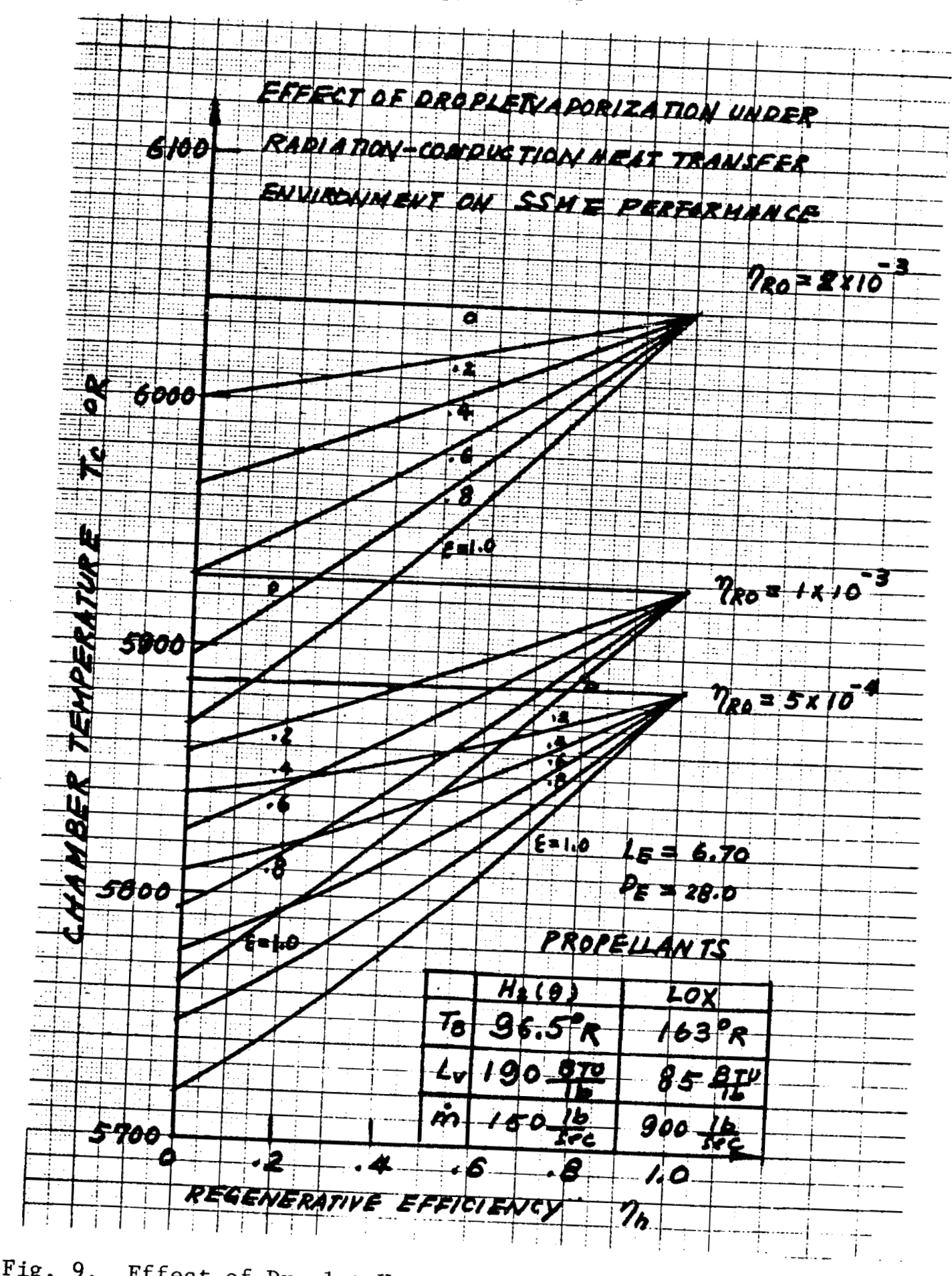

Fig. 9. Effect of Droplet Vaporization Under Radiative-Conductive Heat Transfer Environment on SSME Performance 
ORIGINAL PAGE IS

OF POOR QUALITY

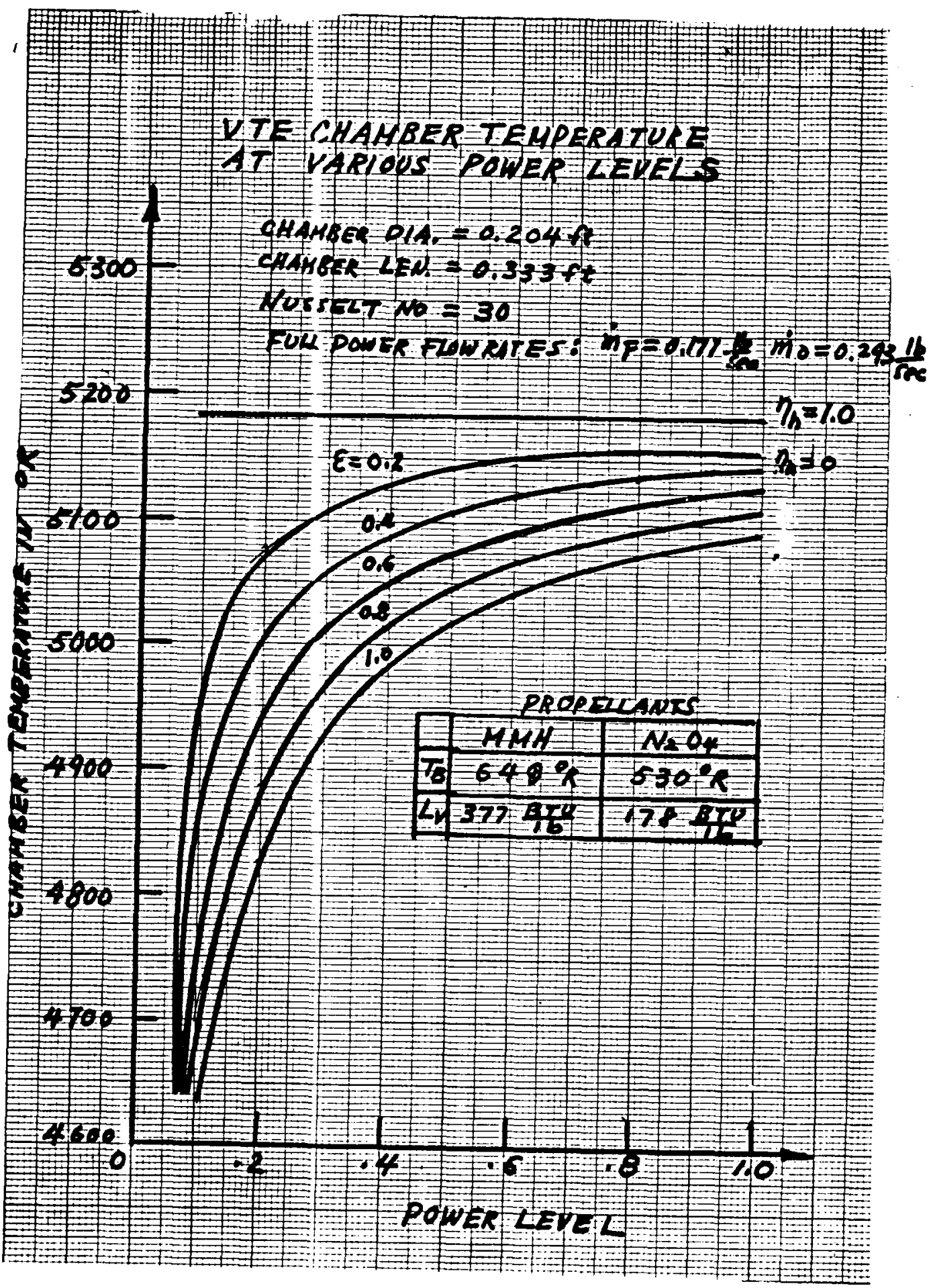

Fig. 10. Effect of Radiation on VTE Chamber Temperature at Various Power Levels 
ORIGINAL PAGE IS

OF POOR QUALITY

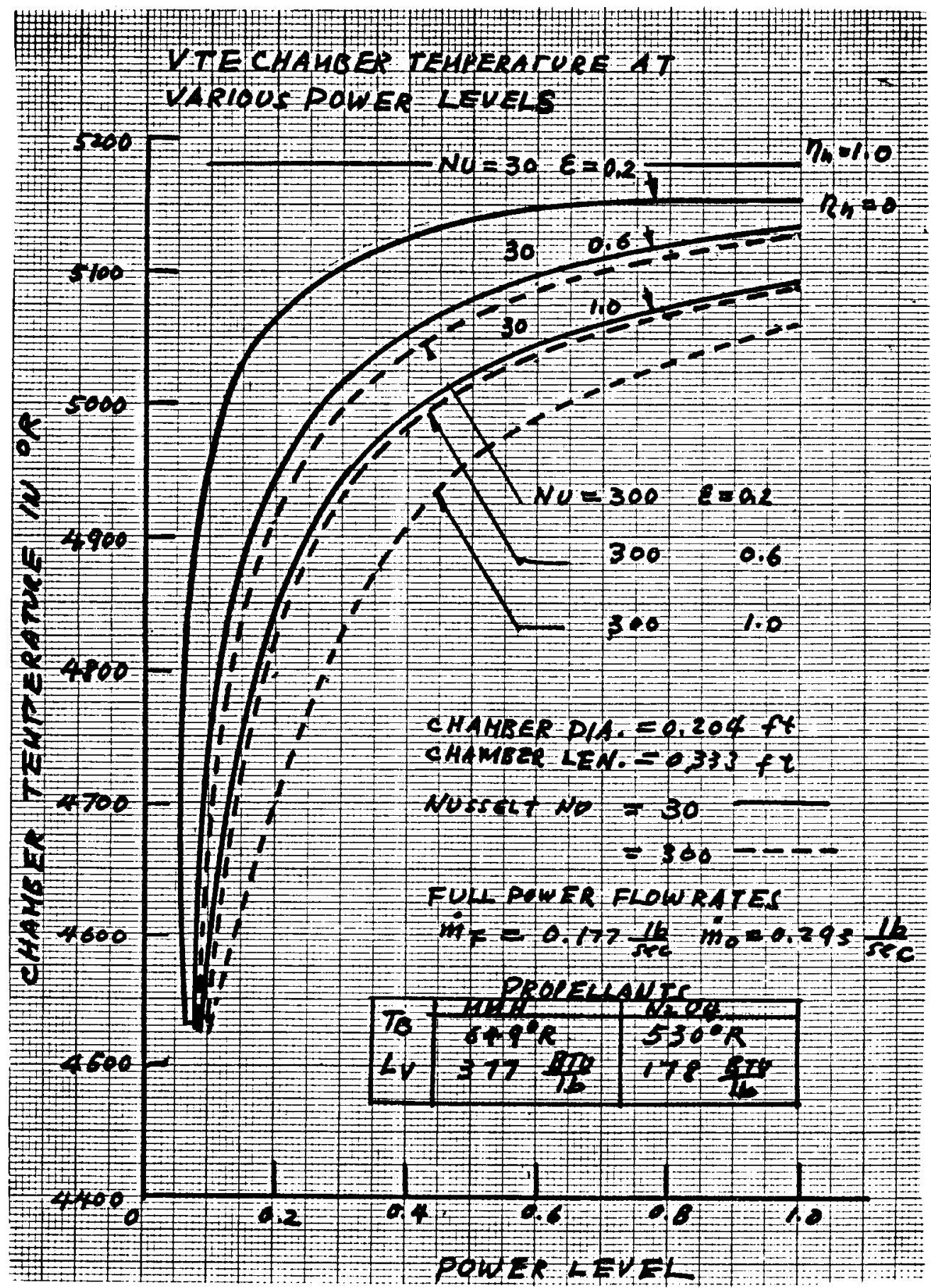

Fig. 11. Effect of Radiation on VTE Chamber Temperature at Selected Nusselt Numbers and at Various Power Levels 


\section{CONCLUSION}

The scaling law coupled with the radiation-enhanced propellant combustion model and associated computational algorithms have been developed to assess the impacts of radiation on the chamber temperature of liquid rocket engines. Two major impacts due to radiation are (1) the reduction in the temperature due to unrecovered radiative conductive and convective heat transfer to the chamber wall with a radiative amount of approximately $70 \%$ of the total loss when the Nusselt number is smaller than a few hundred, and with increasing dominance by a conductiveconvective loss at larger Nusselt numbers, and (2) the gain in the chamber temperature due to the radiation-enhanced gasification rate that tends to increase the combustion efficiency by a few percent over the non-radiating combustion environment.

Based on the characteristics of radiative loss and gain, as presented in the numerical illustration, liquid rocket engines can be classified into high-enthalpy engines, such as the SSME; and low-enthalpy engines, such as the VTE. The performance of the latter type of engines can be significantly impaired by radiative loss at all power levels with high emissivity due to heteropolar gaseous molecules such as $\mathrm{H}_{2} \mathrm{O}, \mathrm{CO}_{2}$, $\mathrm{CO}, \mathrm{NH}_{3}$, and $\mathrm{NO}_{2} \cdot$ A regenerative system with an efficiency higher than $50 \%$ would be required to maintain an acceptable engine performance.

Although the overall combustion efficiency model presented here is crude, and uncertainties of the numerical values adopted may affect the accuracy, the positive impact of radiation-enhanced droplet vaporization appears to be a fundamental consideration in the selection of the propellant and the design of the injector. Much experimental data and extensive modeling, especially with CFD, are required to support the preliminary discoveries.

The overall assessment of the general problem of radiation phenomena in liquid rocket engines clearly indicates the need for research in the following specific problem areas.

(1) Droplet-radiation Interaction - The problems related with the radiative effects on the droplet ignition, combustion, extinction, as well as droplet saturation, condensation of cryogenic and non-cryogenic propellants, are of basic importance in radiation-coupled spray combustion. The effects of the collective interaction phenomena can significantly alter the radiation beam penetration, scattering, absorption, and emission. Droplets near walls, in envelope flames, and recirculation zones are subject to specific radiation view factors which can promote or impair the gasification rates. 
(2) Turbulence-Radiation Interaction - High temperature, high intensity turbulence in the combustion zone provokes turbulence-radiation interaction when the radiative cooling takes part in viscous dissipation and heating. In particular, when the wavelength of the radiation is comparable to the scale of the turbulence, the intercoupling could contribute strongly to the radiative decay of turbulence. Many of these effects are anticipated to depend on the molecular properties, the chamber pressure, and temperature. Heterogeneous mixtures, soot particles and droplets which have high emissivity and absorptivity are also important factors in the local turbulence-radiation interaction.

(3) Flame-Radiation Interaction - Thermal emission and chemiluminescense in a flame zone are the cause of the radiative cooling in optically thin flames. The cooling impairs the flame stability characteristics. Many of these phenomena depend on the molecular and thermochemical properties of the gas mixture in the preheating and combustion zones. In assessing the interaction between the flame and radiation, one needs to differentiate premixed versus diffusion/mixing controlled flames because the heat release rate and the cooling rate in each type of flame are characteristically different. This suggests that the flame extinction characteristics in the two types of flames are different. Additionally, the presence of soot particles in the flame environment affects the emissivity and absorptivity of the mixture. Systematic studies of these fundamental processes under typical rocket engine operating conditions are still lacking at present.

The prediction of combustion processes in a radiative environment requires an advanced spray combustion CFD code that is coupled with a radiative transfer subcode. The latter accounts for the non-equilibrium radiation transport processes. In addition, combustion submodels including radiative droplet laws, atomization processes, turbulence models, gas phase combustion, as we11 as emissivity, absorptivity models in super or subcritical states under radiation effects must be supplemented. Finally, new computational techniques based on finite difference schemes for conventional CFD and special computational techniques such as multi-flux schemes must be effectively incorporated. In addition, the initial and boundary conditions must be supplied to formulate a we11-posed computational problem. 


\section{REFERENCES}

Afgan, N. H. and J. M. Beer, Editors, Heat Transfer in Flames, John Wiley \& Sons, New York, NY (1974).

Bartz, D. R., "Factors Which Influence the Suitability of Liquid Propellants as Rocket Motor Regenerative Coolants," Jet Propulsion, Vo1. 28, pp. 46-53 (Jan. 1958).

Chiu, H. H., "Theory of Bipropellant Combustion, Part I," AIAA-86-0220, AIAA 24th Aerospace Sciences Meeting, Reno, NV (1986a).

Chiu, H. H., et al., "Analytical Prediction of Combustion Performance Characteristics of Bipropellant Liquid Rocket Engine Combustor," JANNAF Combustion Meeting (1986b).

Hottel, H. C., "Engineering Calculations of Radiant Heat Exchange," Turbulent Flows and Heat Transfer, C. C. LIn, Editor, Vol. V, High Speed Aerodynamics and Jet Propulsion, Princeton University Press, Princeton, NJ (1959).

Priem, R. J., "Propellant Vaporization as a Criterion for Rocket Engine Design," NASA TN 3883 (1958).

Sutton, G. P. and D. M. Ross, Rocket Propulsion Elements, John Wiley \& Sons, New York, NY (1975).

Summerfield, M., "The Liquid Propellant Rocket Engine Liquid Propellant Rockets," Editor D. Altman, No. 1., Princeton Aeronautical Paperbacks, Princeton University Press, Princeton, NY (1960).

Williams, F. A., Combustion Theory, Benjamin/Cumming Publishing Co., Inc., Menlo Park, CA (1985). 
PAUL CHIU'S RADIATION COMPUTER MODEL

DIMENSION ETAREG(11), $\operatorname{GRAD}(10), \operatorname{INCL}(2), \operatorname{ETARF}(10), \operatorname{ETARO}(10)$

DATA FTLBTU $/ 778.16 /$, GC $/ 32.174 \%, \mathrm{KG}, \mathrm{LE}, \mathrm{MF}, \mathrm{NO} / 4 * 1 / \mathrm{PI} / 3.141592653 /$,

$1 \mathrm{IP}, \mathrm{IRAD} / 0,0 /, \mathrm{MAX}, \mathrm{MAXR} / 2 \star 50 /, \mathrm{TOL} / 0.0020 \%, \mathrm{INCL} / \mathrm{IXXCL}^{\prime}$, 'INCL'/

REAL ITLIM, KCOND, KP, LENGTH, LF, LO, MDOTF , MDOTO, NUSSEL

ANK $8 / 88$

ANK $8 / 88$

ANK $8 / 88$

C

NAMELIST /PAUL/CPFI,CPOI, CPPROD, DIAM, ETAC,ETAREG, ETARF,ETARO, /PAUL/

1

$\frac{1}{2}$

2

ETAVF, ETAVO, ETAWAL , GRAD , I P, I RAD, I TL IM , KCOND, KG , LE, LENGTH , LF , LO , MAX, MAXR, MDOTF, MDOTO, MF , NO, NUSSEL,

/PAUL/ QCOMB, SIGMA, TBF, TBO, TFI, TOI, TOL, TWALL, ALPHA, PHI, QE /PAUL/

C

READ $(5$, PAUL $)$

PHI $=$ MDOTO/MDOTF

PHI $1=1.0+\mathrm{PHI}$

$\mathrm{QE}=\mathrm{ETAC} \star \mathrm{PHI} 1 * \mathrm{QCOMB}-\mathrm{ETAVF}^{*} \mathrm{LF}-\mathrm{ETAVO}$ *LO*PHI

$A L P H A=K C O N D \star L E N G T H \star N U S S E L \star P I /(2.0 * C P P R O D * F T L B T U \star G C \star M D O T F * P H I 1)$ WRITE $(6,2)$ INCL (IRAD+1)

2 FORMAT (//20X,'PROPELLANT VAPORIZATION AFFECTED BY RECENERATED HEAA

$1 \mathrm{~T}$ (ETAREG) ',A4,'UDING RADIATION' $/ /$ )

WRITE $(9,2)$ INCL (IRAD+1)

WRITE $(6$, PAUL $)$

WRITE $(9$, PAUL $)$

DO $40 M=1, M F$

DO $40 \mathrm{~N}=1$, NO

DO $40 \mathrm{~K}=1, \mathrm{KG}$

WRITE $(9,6)$

6

FORMAT $(/)$

DO $40 \mathrm{~L}=1, \mathrm{LE}$

$J=0$

$\mathrm{TC1}=0.0$

5 BETA $=$ DIAM*GRAD $(K) \star L E N G T H * P I * Q E * * 3 * S I G M A /(3600.0 * C P P R C D * \star 4 * M D O T F$

1 $\star$ PHI $1 * \star 4)$

$A L P H A P=A L P H A *(1.0-\operatorname{ETAREG}(L))$

BETAP $=$ BETA $*(1.0-\operatorname{ETAREG}(L))$

GAMMAP $=$ BETAP $/($ ALPHAP +1.0$)$

CPROPI $=($ CPFI + CPOI*PHI $) / P H I 1$

$T P R O P I=($ CPFI*TFI + CPOI*PHI*TOI $) /(\mathrm{CPFI}+\mathrm{CPOI} * \mathrm{PHI})$

THETAI $=$ CPROPI $* P H I 1 \star T P R O P I / Q E$

THETAW $=$ CPPROD* PHI 1 *TWAL $/ Q E$

KP $=(1 .+$ ALPHAP $*$ THETAW + BETAP $*$ THETAW $\star 4+$ THETAI $) /($ ALPHAP +1.$)$ $Q C=K P$

$I=1$

$10 \mathrm{REST}=$ GAMMAP ${ }^{\mathrm{Q}} \mathrm{QC} \star 4+Q C-K P$

IF (ABS (REST) .LT. ITLIM .OR. I .GT. MAX) GO TO 30

IF (I . GE. 2) GO TO 20

$Q C 1=Q C$

REST1 = REST

$I=2$

$Q C=1.20 * Q C$

GO TO 10

$20 \quad \mathrm{QC2}=\mathrm{QC1}$

REST2 2 REST1

QC1 $=\mathrm{QC}$

REST1 $=$ REST

IF (ABS(REST2 - REST1) .LE. 0.0$)$ GO TO 30

$Q C=Q C 1-\operatorname{REST} 1 *(Q C 2-Q C 1) /(\operatorname{REST} 2-\operatorname{REST} 1)$

$I=I+1$

GO TO 10

$30 \mathrm{TC}=\mathrm{QC} \star \mathrm{QE} /\left(\mathrm{CPPROD}{ }^{*} \mathrm{PHI} 1\right)$

IF (IRAD.EQ. 0 ) GO TO 35

C RADIATION IS TO BE INCLUDED

TC2 $=$ TC1

$\mathrm{TC1}=\mathrm{TC}$

ANK $7 / 88$

ANK $7 / 88$

ANK $7 / 88$

ANK $7 / 88$

ANK $7 / 88$

ANK $8 / 88$

AANK $8 / 88$

ANK $8 / 88$

ANK $8 / 88$

ANK $7 / 88$

ANK $8 / 88$

ANK $8 / 88$

ANK $8 / 88$

ANK $8 / 88$

ANK $8 / 88$

ANK $8 / 88$

ANK $8 / 88$

ANK $8 / 88$

ANK $8 / 88$

ANK $8 / 88$

ANK $7 / 88$

ANK $8 / 88$

ANK $8 / 88$

ANK $8 / 88$

ANK $7 / 88$

ANK $7 / 88$

ANK $7 / 88$

ANK $7 / 88$

ANK $8 / 88$

ANK $7 / 88$

ANK $7 / 88$

ANK $7 / 88$

ANK $7 / 88$

ANK $7 / 88$

ANK $7 / 88$

ANK $7 / 88$

ANK $7 / 88$

ANK $7 / 88$

ANK $7 / 88$

ANK $7 / 88$

ANK $7 / 88$

ANR $7 / 88$

ANK $7 / 88$

ANK $7 / 88$

ANK $7 / 88$

ANR $7 / 88$

ANK $7 / 88$

ANK $7 / 88$

ANK $8 / 88$

ANK $8 / 88$

ANK $8 / 88$ 
PROGRAM LISTING (Continued)

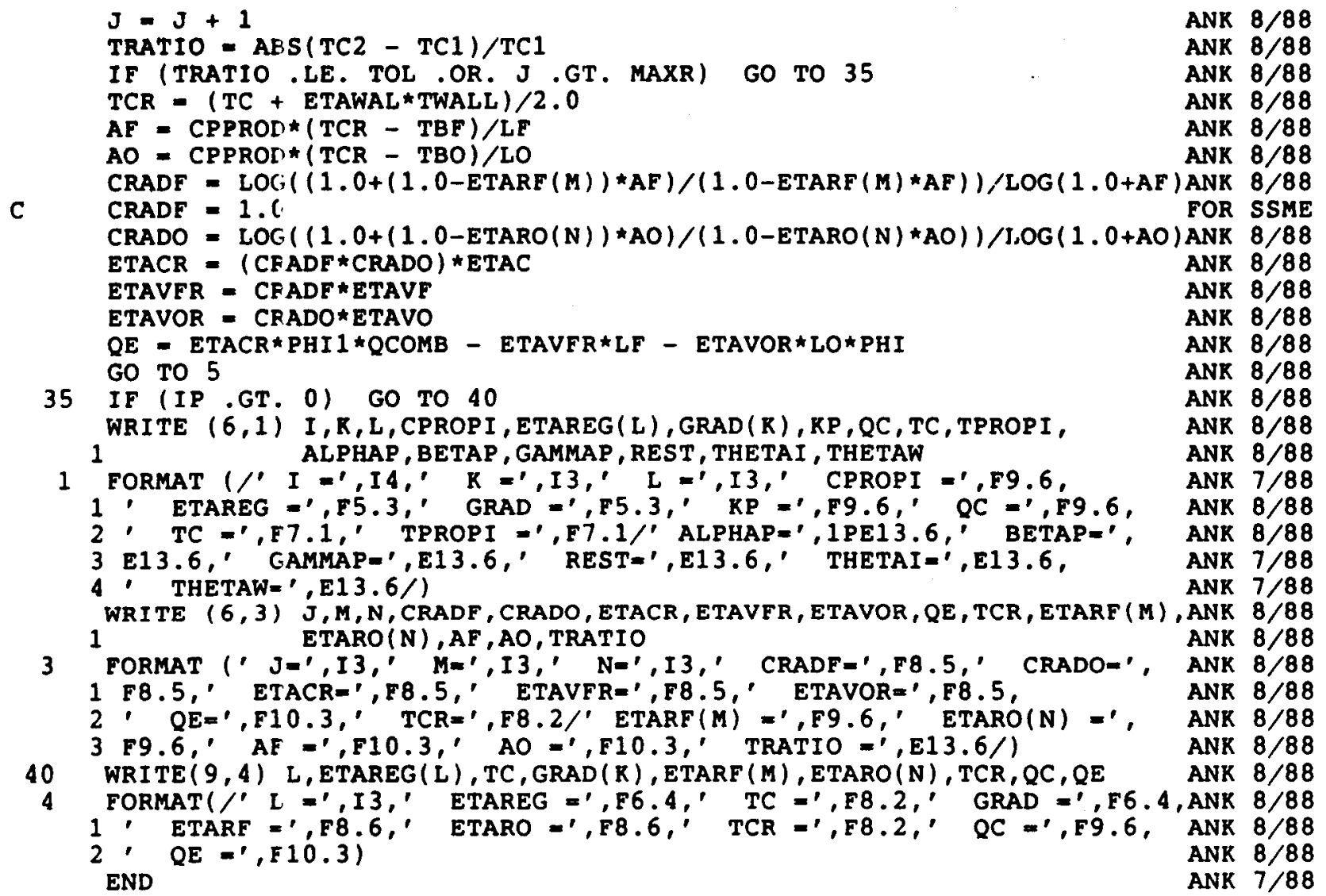

INPUT DATA

\$PAUL

CPEI $=0.70$, CPOI $=0.3780$, CPPROD $=1.650$, DIAM $=0.20412$, ETAC $=0.920$, ETAREG $=1, \ldots 9, .8, .7, .6, .5, .4, .3, .2, .1, .0$, ETAVF $=.94$, ETAVO $=.95$, IRAD $=1$, GRAD $=1.0,0.8,0.6,0.4,0.2,0.0$, ITLIM $=1.0 \mathrm{E}-10, M F=1$, NO $=1$, KCOND $=2.0, K G=6, L E=11$, LENGTH $=0.33333, \mathrm{LF}=377.0, \mathrm{LO}=178.20$, MDOTF $=0.1415728$, MDOTO $=0.2345336$, NUSSEL $=300.0$, QCOMB $=8910.0$, SIGMA $=1.7120 \mathrm{E}-9$, TFI $=460.0$, TOI $=460.0$, TWALL $=2500.0$, TOL $=0.0020$, ETAWAL $=1.0$, ETARF $=.008, .01$, ETARO $=.0005, .001$, TBF $=649.0$, $T B O=530.0$, \$END 